\title{
RECENT ADVANCES IN THE APPLICATION OF CAPILLARY \\ ELECTROMIGRATION METHODS FOR FOOD ANALYSIS
}

\author{
Alejandro Cifuentes \\ Department of Food Analysis, Institute of Industrial Fermentations (CSIC), \\ Juan de la Cierva 3, 28006 Madrid, Spain
}

Running title: Food analysis by CE

Corresponding author: Alejandro Cifuentes

Address: c/ Juan de la Cierva 3, 28006 Madrid, Spain.

e-mail: acifuentes@ifi.csic.es; Fax\# 34-91-5644853; Phone\# 34-91-5622900 (ext. 387)

Abbreviations: BGE, background electrolyte; CE-AD, capillary electrophoresis with amperometric detection; CE-CD, capillary electrophoresis with conductivity detection; CGE-LIF, capillary gel electrophoresis with laser induced fluorescence; D-IAA, D-isoascorbic acid; DNS, dansyl chloride; FITC, fluorescein isothiocianate; FQ, 3-(2-furoyl)quinoline-2-carboxaldehyde; GABA, $\gamma$-aminobutyric acid; GMO, genetically modified organism; HAA, heterocyclic aromatic amines; L-AA, L-ascorbic acid; MEEKC, microemulsion electrokinetic chromatography; MRLs, maximum residue limits; OPA, o-phthaldialdehyde; PCR, polymerase chain reaction ; SC, sodium cholate.

Keywords: capillary electrophoresis, foods, review, CE, CEC, MEKC, proteins, amino acids, peptides, DNAs, phenols, pesticides, toxins, additives. 


\begin{abstract}
This article reviews the latest developments in the application of capillary electromigration methods for the analysis of foods and food components. Nowadays, methods based on capillary electrophoresis (CE) techniques are becoming widely used in food analytical and research laboratories. This review covers the application of CE to analyze amino acids, biogenic amines, peptides, proteins, DNAs, carbohydrates, phenols, polyphenols, pigments, toxins, pesticides, vitamins, additives, small organic and inorganic ions, chiral compounds, and other compounds in foods, as well as to investigate food interactions and food processing. The use of microchips as well as other foreseen trends in CE analysis of foods are discussed. Papers that were published during the period June 2002-June 2005 are included following the previous review by Frazier and Papadopoulou (Electrophoresis 2003, 24, 4095-4105).
\end{abstract}




\section{CONTENTS}

1. Introduction

2. Amino acids and biogenic amines

3. Proteins and peptides

4. Phenols, polyphenols and pigments

5. Carbohydrates

6. DNAs

7. Vitamins

8. Small organic and inorganic acids

9. Toxins, contaminants, pesticides and residues

10. Food additives

11. Food interactions and processing

12. Chiral analysis of foods compounds

13. Other applications

14. Microchips and other future trends in food analysis

15. References 


\section{INTRODUCTION.}

New analytical techniques must address an important number of problems in food science providing information about processing, quality control, ensuring compliance with food and trade laws, adulteration, contamination, product tampering, chemical composition of foods, etc. Moreover, the increased consumers concern about what is in their food and the safety of the food they eat has brought about the necessity of developing new analytical techniques able to face these new challenges. Therefore, faster, more powerful, cleaner and cheaper analytical procedures are being required by food chemists, regulatory agencies and quality control laboratories to meet these demands.

Among the different analytical techniques that can be employed to analyze foods and food compounds (e.g., HPLC, GC, etc), the use of capillary electrophoresis (CE) has emerged as a good alternative since this technique provides fast and efficient separations in this type of analysis. CE is based on the different electrophoretic mobilities of substances in solution under the action of an electric field. The main properties of CE are high speed of analysis, high separation efficiencies, great variety of applications, and additionally, reduced sample and solvents consumption. These characteristics have contributed to the rapid development of CE.

Although compared with GC or HPLC, CE can be considered as a technique relatively new in food analysis, a large variety of foods have already been analyzed by this technique. Thus, water, beverages, fruits, vegetables, milks, meats, cereals, etc, have been analyzed by CE. Moreover, CE can also be used to monitor food changes such as oxidation, amino acid racemization or other changes on chemical composition during cooking, processing, storage, microbial contamination, etc, what clearly demonstrates the versatility of this technique. Several reviews have been published on the application of CE methods in food analysis in the last three years, which is a good 
demonstration of the possibilities of this technique in this particular field. Table 1 summarizes the different reviews published on this topic [1-19], including the aforementioned review by Frazier and Papadopoulou [1].

The goal of this review is to examine the latest developments in the application of capillary electromigration methods for the analysis of foods and food components, including amino acids, biogenic amines, peptides, proteins, DNAs, carbohydrates, phenols, polyphenols, pigments, toxins, additives, vitamins, small organic and inorganic ions, chiral compounds, pesticides and other residues in foods, as well as to investigate food interactions and food processing. As indicated above, papers are reviewed that were published during the period June 2002-June 2005 following the previous review by Frazier and Papadopoulou [1].

\section{AMINO ACIDS AND BIOGENIC AMINES.}

Analysis of amino acids in foods has been demonstrated to provide interesting information on food quality, processing, adulterations, proteins composition, etc. In a recent work [20], the unusual amino acid levodopa (3,4-dihydroxyphenylalanine) has been determined by CE in broad bean and lentil. Levodopa is the precursor required by the brain to produce dopamine, a neurotransmitter (chemical messenger in the nervous system). People with Parkinson's disease have depleted levels of dopamine and levodopa is used to increase dopamine in the brain, which reduces the symptoms of Parkinson's disease. The dependence of effective mobility of levodopa on $\mathrm{pH}$ was investigated in the range of 1.64-11.20, and the simulated apparent dissociation constant values obtained by CE were consistent with literature values [20].

Protein hydrolysates have multiple applications in food science and cosmetics. Amino acids have been analyzed in protein hydrolysates by CE [21] using two chromophores, 3,5-dinitrobenzoate and 
phthalate, and $\alpha$-cyclodextrin and methanol as additives. The goal was to develop different background electrolytes (BGEs) for the CE analysis of free underivatized amino acids in commercially available protein hydrolysates from keratin, silk fiber, milk, soybean, fish tissue, and cattle leather. Sixteen amino acids could be effectively separated by two distinct CE methods [21].

Two different CE methods have been developed by Komarova et al [22] to analyze amino acids in fodders and raw materials. The first CE method provided analysis of four technologically important amino acids (lysine, methionine, threonine, cystine) in borate buffer based on characteristic absorption of amino group (190 nm), with limits of quantitation being on average $0.2 \%$. The second CE method included pre-capillary derivatization of amino acids using phenylisothiocyanate and separation of phenylthiocarbamyl-derivatives obtained by CZE with a detection on $254 \mathrm{~nm}$, which allowed to widen a list of detectable components up to 19 (without tryptophan) and significantly improved detection limits down to $0.01 \%$. The results of analysis of fodders were compared with ion exchange chromatography (amino acid analyzer) and reversed-phase (RP)-HPLC (with gradient technique of elution) showing in general a good agreement.

Klampl and Vo [23] have carried out a comparison of CE techniques with indirect UV, direct UV, and mass spectrometric detection for the determination of underivatized amino acids and vitamin B6 in infusion solutions. Acidic and basic carrier electrolytes were investigated with respect to their suitability for the separation of the selected analytes. Indirect and direct UV detection at different wavelengths, as well as MS detection were tested, with the main emphasis set on their ability to provide quantitative results for all analytes in a single run. An acidic carrier electrolyte based on phosphoric acid and direct UV detection at $195 \mathrm{~nm}$ were found to be the best suited condition for the determination of the amino acids and vitamin B6 in the investigated real samples. 
Amino acids can be analyzed by capillary electromigration methods as underivatized compounds or, more frequently, after derivatization. Although it is clear that derivatization of amino acids introduces an additional analytical step, it has repeatedly been demonstrated that derivatization can bring about interesting advantages during the analysis of these molecules. Thus, apart of the evident sensitivity enhancement that can be achieved by using adequate probes together with fluorescence detection [24,25], derivatization frequently facilitates the chiral separation of amino acids, since inclusion and interaction with the chiral selector becomes more discriminating. This is frequently not only due to the increase in size but also due to the new interactions involving the label [26]. Moreover, derivatization provides a better sensitivity for analysis by ESI-MS, since the resulting larger molecules can be ionized with a higher yield and molecular mass increases till a mass range ( $>150 \mathrm{~m} / \mathrm{z}$ ) where the MS background noise is usually lower [26]. Our group has developed different methods based on micellar electrokinetic chromatography with laser induced fluorescence detection (MEKC-LIF) [24,25] and CE-mass spectrometry (CE-MS) [26] to analyze dansyl chloride (DNS) and fluorescein isothiocianate (FITC) derivatized amino acids in orange juices. A representative group of 14 D-and L-amino acids was selected (i.e., D/L-Asp, Glu, Ser, Asn, Ala, Pro, Arg) plus the nonchiral $\gamma$-aminobutyric acid (GABA). Two reasons were behind the selection of this group of 15 amino acids: (i) they are a good representation of the different types of amino acids that can be found in nature (i.e., chiral and positively charged as Arg, neutral as Ala, Pro, Ser, Asn, negatively charged as Asp, Glu, and nonchiral as GABA); (ii) the mentioned group is responsible for more than $90 \%$ of the amino acidic content in orange juices. As an example of the good possibilities of CE to analyze these compounds, Figure 1 shows the MEKC-LIF analysis of the 15 selected amino acids.

Detection of biogenic amines is nowadays a hot topic in food safety. These compounds, produced from bacterial and/or enzymatic degradation of some amino acids in foods, have been demonstrated to be toxic. For this reason, the development of fast analytical procedures based on CE for the 
determination of biogenic amines in foods has increased in the last years. Recent applications of CE to the analytical determination of biogenic amines include analysis of histamine and tyramine derivatized with OPA and analyzed using CE-LIF [27]. Putrescine, cadaverine, spermidine and spermine were separated and quantified by CE with pulsed amperometric detection in milk [28]. Tryptamine, tyramine and their precursor amino acids (tryptophan and tyrosine) were analyzed in a rice spirit by MEKC with amperometric detection [29]. Also, histamine was detected by CE with diode array detector in tuna with limits of detection and quantification of 0.5 and $1.0 \mathrm{mg} / \mathrm{kg}$, respectively [30]. Spermine, spermidine and putrescine were determined (as N-benzamides) in various foods by using MEKC [31]. It is interesting to mention that 153 samples, corresponding to 21 types of foods, were tested in that work [31]. Results showed that fresh green pepper, grapefruit and stewed green peas contained the highest mean levels of putrescine ( $>55 \mathrm{mg} / \mathrm{kg}$ ), while kidney, pork liver and processed meats contained very low putrescine levels. Foods of animal origin contained higher levels of spermine than spermidine, while for plant foods, the opposite association was observed. Roasted chicken breast, yellow pea puree, stewed green peas and dry soybeans contained mean spermidine contents $>20 \mathrm{mg} / \mathrm{kg}$. Mean spermine contents above the same level were observed in roasted pork neck, roasted pork liver, stewed pork kidney and roasted chicken breast [31]. A new procedure based on the use of pressure-assisted monolithic octadecylsilica capillary electrochromatography-mass spectrometry was developed to determine aliphatic amines in water samples [32]. This CEC-MS separation was achieved by simultaneously applying a CE voltage of $13 \mathrm{kV}$ and an overimposed pressure of 8 bars. Use of pressure was required to ensure stable electrospray conditions. The proposed method was applied to the determination of low molecular weight aliphatic amines in tap water and river water. Analysis of real samples required cleanup and preconcentration that could be performed automatically by inserting a minicolumn in the replenishment system of the commercial instrument [32]. 


\section{PROTEINS AND PEPTIDES.}

Analysis of proteins and peptides is one of the main applications of CE also in food science. Thus, Table 2 summarizes the works found in literature on this topic along the period covered in this review including some experimental conditions. From Table 2 it can be concluded that the main application areas of CE in food proteins and peptides are the following: The first one would refer to the use of CE to analyze proteins from milk and dairy products [33-41], the second one would cover the analysis of proteins from cereals (mainly wheat proteins) [42-49], and the third one would include all the other applications [49-55].

Although separation of proteins has nowadays become one of the main applications of CE, separation of these biopolymers using fused-silica capillaries is strongly hampered by solute adsorption onto the capillary wall. Adsorption of proteins onto capillary wall is one of the main reasons for observed efficiency loss, poor reproducibility in migration times and low protein recovery rates. Adsorption is generally due to electrostatic interactions between positively charged residues of the proteins and negatively charged silanol groups, which are intrinsic to the fusedsilica surface of uncoated capillaries. Our group has developed a simple, fast and reproducible coating physically adsorbed onto the capillary wall [33]. The coating polymer, composed of N,Ndimethylacrylamide-ethylpyrrolidine methacrylate, was demonstrated to provide good CE separations of acidic and basic proteins, including proteins from whey. Coating regeneration was achieved just by flushing the capillary between injections with an aqueous solution of this polymer [33].

Miralles et al [36] used CE to study the degree of proteolysis caused by storage of raw and UHT milk. Similar approach was used by Pellegrino et al [37] in order to analyze the patterns of 
proteolysis in Grana Padano cheeses. Also, similar CE method was applied to detect the illegal addition of goat milk and/or cow milk in Halloumi cheese based on the electrophoretic profiles of the casein fraction [38]. A new CE approach was recently presented [40] in which the main whey proteins were derivatized on-capillary with 3-(2-furoyl)quinoline-2-carboxaldehyde (FQ) and analyzed using a laboratory-made CE apparatus provided with a laser-induced fluorescence detector. Several parameters controlling on-capillary derivatization of proteins, including $\mathrm{pH}$, mixing time, reaction time, concentration of the reagents (potassium cyanide and FQ), and reaction temperature, were optimized. Assay detection limits for the different proteins were in the range 5 $\mathrm{nM}$ to $10 \mathrm{nM}$. The method developed was applied to the separation of the major whey proteins in a laboratory-made cheese whey [40] and in infant foods formulated with milk [41].

Analysis of cereal proteins (mostly from wheat) is an important issue not only due to the nutritious implications of these biopolymers but also because some of these proteins (as e.g., enzymes) can have an important impact on end-use quality of the grain including food functionality, food coloration, and matting quality. Most research concerning grain proteins has concentrated on the gluten storage proteins. However, the albumins and globulins (i.e., water- and salt-soluble proteins) that contain biologically active enzymes and enzyme inhibitors have also been investigated by CE [42]. Apart of the numerous CE studies concerning the analysis of proteins from wheat [43, 45-49], authors have also investigated the content of proteins (namely, hordeins) in barley [44].

CE has also been applied to analyze peptides and proteins in other foods different than dairy products and cereals. Thus, analysis of cider proteins was carried out by using capillary gel electrophoresis (CGE) with linear polyacrylamide as sieving medium [50]. After testing four different sample treatments, purified cider proteins were analyzed by CGE obtaining information on the molecular weight of the proteins detected. It was discussed that proteins content in cider 
influences foam behavior and haze formation, and may also be used to characterize the geographical origin of a cider.

Regarding the analysis of peptides and proteins by CE methods, our group has demonstrated the great possibilities of CE-MS as a tool for Proteomics in food science and technology. This includes the detection and quantitation of a bioactive peptide in Vicia narbonensis L. seeds [51], the characterization of proteins from Spirulina platensis microalga using CE-ion trap-mass spectrometry and CE-time of flight-mass spectrometry [52], the CE-MS analysis of basic proteins in foods using a new physically adsorbed polymer coating [53] and the investigation of peptidic maps from proteins using CE-MS and a peptide modelling [54].

\section{PHENOLS, POLYPHENOLS AND PIGMENTS.}

Analysis of phenols, polyphenols and pigments in foods is important because of their contribution to the color, taste and flavor characteristics. Recently, these compounds have been the object of increasing interest because of their good biological properties, namely as antioxidants, antiinflammatory, anti-histaminic and/or anti-tumor, and as free radical scavengers and protection against cardiovascular diseases. There is increasing evidence to suggest that age-related human diseases, such as heart disease, cancer, immune system decline and brain dysfunction are result of cellular damage by free radicals. These antioxidants in our diet could play an important role in such disease prevention, which has fueled much public interest in natural antioxidants and has led to an extensive search for effective antioxidants in nature especially those present naturally in human diets. CE can play a crucial role as a simple, economical and accurate method for the determination of these compounds in foods. It can also be deduced from the large number of CE applications on phenols, polyphenols and pigments [56-81] (i.e., this is the main application of CE together with the analysis of proteins and peptides). These CE applications can be divided attending to the sample 
analyzed. Thus, grapes and wines [56-61], plants (including spices and medicinal herbs) [62-68], different teas $[58,69,70]$, and olive oils [71-74] are the sources of phenols, polyphenols and pigments mainly investigated. However, some others natural samples such as berries [75], fruits [76,77], soy [78], alga and microalga [79,80] and chocolate [81] have also been analyzed by CE.

Nine flavonoids frequently found in wine (apigenin, baicalein, luteolin, naringenin, hesperetin, galangin, kaempferol, quercetin and myricetin), and their potential precursor, caffeic acid, were analyzed by CE-UV [56]. Analysis was performed on fused silica capillaries using $35 \mathrm{mM}$ borax at pH 8.9 as BGE, and monitoring at $250 \mathrm{~nm}$. This method gave successful resolution of the 10 analytes and allowed the analysis of wine samples prepared by solid phase extraction [56].

Simultaneous determination of trans-resveratrol, (-)-epicatechin and (+)-catechin in red wine has been carried out by CE with electrochemical detection (CE-ED) [57]. Effects of the potential of the working electrode, $\mathrm{pH}$ and concentration of running buffer, separation voltage and injection time on CE-ED were investigated. Under optimum conditions, the analytes were separated in a $100 \mathrm{mM}$ borate buffer at pH 9.2 within 20 min. A $300 \mu$ m diameter disk electrode exhibited a good response at $+0.85 \mathrm{~V}$ for all analytes. The response was linear over 3 orders of magnitude with detection limits (signal to ratio of 3) ranging from $2 \times 10^{-7}$ to $5 \times 10^{-7} \mathrm{~g} / \mathrm{ml}$ for all analytes. It was concluded that this CE-ED method could be used for the determination of trans-resveratrol, (-)-epicatechin and (+)-catechin in red wines.

In a recent work [58], microemulsion electrokinetic chromatography (MEEKC) and MEKC were compared for their abilities to separate and detect thirteen phenolic compounds (syringic acid, pcoumaric acid, vanillic acid, caffeic acid, gallic acid, 3,4-dihydroxybenzoic acid, 4-hydroxybenzoic acid, (+)-catechin, (-)-epigallocatechin, (-)-epicatechin gallate, (-)-epigallocatechin gallate, (-)- 
epicatechin, and (-)-gallocatechin), and two other ingredients (caffeine and theophylline) in grapes and teas. Separation of phenolic compounds was improved by changing the SDS concentration for MEEKC, but the SDS concentration did not affect the resolution for MEKC. Organic modifier (acetonitrile or methanol) was found to markedly influence the resolution and selectivity for both MEEKC and MEKC systems. In addition, a higher voltage and a higher column temperature improved the separation efficiency without any noticeable reduction in resolution for MEEKC, whereas they caused a poor resolution for the MEKC system. Although separations with baseline resolution were achieved by the optimized MEEKC and MEKC methods, the separation selectivity resulting from the proposed MEEKC method was completely different from that of MEKC [58].

Other interesting compounds analyzed in grapes by CE methods have been oligomeric procyanidins [59]. In this case a mixed micellar medium composed of sodium cholate (SC) and SDS (50 mM phosphate at pH 7 containing $40 \mathrm{mM} \mathrm{SC}$ and $10 \mathrm{mM}$ SDS) was used to separate these compounds in less than 15 min. The proposed method is useful to separate the major components of the thiolysate in effluents from food processing (e.g., skins and seeds from grape and apple) considered as potential procyanidin sources [59].

A new MEKC method was developed for simultaneous separation of 6 anthocyanins (malvidin-3,5diglucoside, malvidin-3-glucoside, malvidin-3-galactoside, pelargonidin-3-glucoside, cyanidin-3,5diglucoside and cyanidin-3-galactoside) [60]. Optimum selectivity was achieved using a buffer composed of $30 \mathrm{mM}$ phosphate, $400 \mathrm{mM}$ borate-TRIS at pH 7.0, with $50 \mathrm{mM}$ SDS. High content of borate was essential mainly for separation of diastereomeric pair malvidin-3-glucoside and malvidin-3-galactoside. Good linearity was obtained in the concentration range $10-100 \mu \mathrm{g} / \mathrm{ml}$ for diglycosylated and 25-100 $\mu \mathrm{g} / \mathrm{ml}$ for monoglycosylated derivatives. The optimized method was applied to a sample of wine grape skin extract. Malvidin-3-glucoside was identified as the main anthocyanin in this sample. 
CZE was combined with capillary isotachophoresis (ITP) to increase the separation capability and sensitivity during CZE analysis of fourteen selected flavonoids and phenolic acids in red wine [61]. Optimization of leading and terminating electrolyte for ITP, as well as the BGE for the CZE separation and timing of the transfer of isotachophoretically stacked analyte zones into the CZE column was carried out. Under these conditions a single ITP-CZE analysis took 45 min, with detection limits of $30 \mathrm{ng} / \mathrm{ml}$ for phenolic acids, quercitrin and rutin, $100 \mathrm{ng} / \mathrm{ml}$ for quercetin, kaempferol and epicatechin and $250 \mathrm{ng} / \mathrm{ml}$ for catechin [61].

Garcinia kola, also known as bitter kola, is used in traditional African medicines and in foods, including use as a bitter flavoring in beers and wines. A rapid CE-UV method was developed for the quantification of 4 biologically active biflavanones (GB1, GB2 and GB1-glycoside and kolaflavanone) present in 3 different preparations from the seeds of Garcinia kola [62]. The optimum separation conditions (100 mM borate, pH 9.5 running buffer) gave baseline resolution of the 4 components in less than $12 \mathrm{~min}$. Limits of detection for the biflavanones were between 3 and $6 \mu \mathrm{g} / \mathrm{ml}$. The 'fingerprint' of the biflavanones in the formulations was found to be similar being the major component the biflavone GB1 [62].

The pharmacologically active flavonoids epicatechin, catechin, rutin, kaempferol and quercetin were determined in Hippophae rhamnoides (sea buckthorn) using CE-AD [64]. Effects of several factors, such as the acidity and concentration of running buffer, separation voltage, applied potential and injection time were investigated to find optimum conditions. Detection limits ranged from $1.3 \times 10^{-7}$ to $5.9 \times 10^{-7} \mathrm{mg} / \mathrm{l}$ for all 5 analytes. This method was successfully used in analysis of Hippophae rhamnoides and its phytopharmaceuticals after a simple extraction procedure. 
Iridoid glycosides, flavonoids and phenylethanoids were detected in Verbena officinalis (vervain) using MEKC [65]. Optimum separation was achieved using a $50 \mathrm{mM}$ sodium borate solution (pH 9.3), containing $50 \mathrm{mM}$ SDS as surfactant. Because of their different UV absorption maxima, the compounds were detected either at 205 or $235 \mathrm{~nm}$. Detection limits ranged from $5.0 \mu \mathrm{g} / \mathrm{ml}$ (verbascoside) to $13.6 \mu \mathrm{g} / \mathrm{ml}$ (hastatoside). The 5 compounds were readily assignable in several samples of Verbena.

Rosemary (Rosmarinus officinalis) has been one of the most studied plants as a natural source of antioxidants (carnosic and rosmarinic acid, carnosol, etc) [66-68]. In this area, our group has developed different CE-UV and CE-MS procedures to analyze these polyphenols obtained from rosemary using subcritical water extraction $[66,67]$.

Also theanine, caffeine, and catechins have been determined in different types of tea $[69,70]$, as well as the effects of these compounds on rat [69]. Thus, young tea leaves were found to be richer in caffeine, (-)-epigallocatechin gallate and (-)-epicatechin gallate than old tea leaves. On the other hand, old leaves contained higher levels of theanine, (-)-epigallocatechin and (-)-epicatechin [69]. In a different work [70], the catechins (-)-epicatechin, (-)-epigallocatechin, (+)-catechin, (-)epigallocatechin gallate and (-)-epicatechin gallate, and caffeine were measured in water and methanol extracts of matcha tea and water extracts of a popular common green tea (China Green Tips). Results indicated that drinking matcha tea would provide 137 times more, (-)epigallocatechin gallate than consuming the common brand [70].

Olive oil is an important source of health promoting compounds. Thus, tyrosol, hydroxytyrosol and common phenolic compounds were investigated in extra virgin olive oil using CE [71]. With the optimized CE method, 21 phenolic compounds could be separated in 10 min using $45 \mathrm{mM}$ sodium 
tetraborate buffer at $\mathrm{pH}$ 9.6. There were positive correlations between phenolic compounds detected by CE in oils and results of spectrophotometric analysis of total phenols [71].

Natural chlorophyllic pigments have also been detected in olive oils in order to detect some adulterations [72]. Namely, synthetic chlorophyll, which is produced by replacing the $\mathrm{Mg}$ at the center of porphyrin with a transition element (i.e. a $\mathrm{Cu}$ ion), may also be illegally added to oils to improve their color. In this study [72], a capillary zone electrophoresis method with a laser induced fluorescence detector was developed for the separation of copper chlorophyll from other chlorophyll pigments and its determination in olive oils. Separation occurs in less than 10 min. The method showed to be rapid and sensitive and had good repeatability, reproducibility and accuracy.

Fernandez-Gutierrez's group has made interesting contributions to the analysis of phenolic acids in olive oil $[73,74]$. Thus, determination and quantification of fourteen phenolic acids at ppb levels was carried out in olive oil samples after a liquid-liquid extraction using co-electroosmotic CE with UV detection. In this work [73], a polycationic surfactant (hexadimetrine bromide), which dynamically coats the inner surface of the capillary and causes a fast anodic electroosmotic flow, was added to the electrolyte. Also, a new CE method was developed to separate the phenolic acids trans-cinnamic acid, 4-hydroxyphenylacetic acid, sinapinic acid, gentisic acid, (+)-taxifolin, ferulic acid, o-coumaric acid, p-coumaric acid, vanillic acid, caffeic acid, 4-hydroxybenzoic acid, dopac, gallic acid and protocatechuic acid in $16 \mathrm{~min}$. The presence of many of these compounds was detected in eight different types of oils as shown in Figure 2 [74] .

MEKC has been also applied by our group to investigate the composition of pressurized liquid extracts obtained from Spirulina platensis microalga as a natural source of nutraceuticals, correlating the composition of the extracts with their antioxidant activity measured using in-vitro analysis [79]. Also, bioactive ingredients in the brown alga Fucus vesiculosus have been analyzed 
by CE [80]. In that work [80], polyphenols (phlorotannins) were analyzed by CE using UV detection at $210 \mathrm{~nm}$ and an uncoated silica capillary using borate or acetate buffer in a methanol/acetonitrile mixture as BGE.

\section{CARBOHYDRATES.}

Carbohydrates are essential to metabolism since they act in plants and animals as energy and carbon sources; they are also important structural elements in plant cell walls as well as in the extracellular matrix of animal and human tissues; as integral components of glycoproteins and glycolipids, carbohydrates are involved in many biological processes. Reducing carbohydrates such as sucrose, glucose, and fructose are among the key biological substances involved in many life processes. They also exist widely in many foods and beverages, and are often used as food additives. As a result, the monitoring of carbohydrates by CE is increasingly important in nutrition, biology, and food science, as corroborated by the good number of papers lately published on this topic [82-94].

However, carbohydrate analysis by CE can encounter difficulties such as lack of electric charge and absence of a chromophore/fluorophore in the analyte molecules. In order to overcome these limitations some interesting instrumental and methodological developments for CE of carbohydrates have been proposed. For instance, CE can be directly used for the analysis of partially methyl-esterified oligogalacturonides improving in that way resolution and molecular absorbance of individual oligomers [82]. Following similar strategy, reductive amination of aldoses at the carbonyl group has been used [83]. Namely, a chromophore (using tryptamine) is introduced to the carbohydrates enabling their identification and sensitive UV detection at $220 \mathrm{~nm}$ based on the indole group. In that work [83], 12 carbohydrates, including pentoses (D-ribose, L-arabinose and D-xylose), hexoses (D-glucose, D-mannose and D-galactose), deoxy sugars (L-rhamnose and 
L-fucose), uronic acids (D-glucuronic acid and D-galacturonic acid) and disaccharides (cellobiose and melibiose) were included, using D-thyminose (2-deoxy-D-ribose) as the internal standard. Detection of all 12 carbohydrates in the picomole range was performed within 30 min using MEKC. Also, carbohydrates have been derivatized with benzylamine, quaternized and separated in ammonium acetate buffer with on-column UV detection [84]. This approach facilitated capillary electrophoretic separation of neutral oligosaccharides and structural isomers.

An alternative strategy is the use of indirect UV detection to monitor carbohydrates by CE. This approach was applied to evaluate the prebiotic properties of fructooligosaccharides and inulin [87] and to detect the natural anionic polysaccharide fucoidan in marine brown algae [88]. In the latter application [88], sulfosalicylic acid or anisic acid were added as chromophores to the BGE. The use of indirect UV detection was also applied to analyze sucrose, raffinose, stachyose, verbascose and ajugose in Leguminosae and Brassicaceae [89]. These carbohydrates were determined using pyridine-2,6-dicarboxylic acid as BGE in a sodium tetraborate buffer with cetyltrimethylammonium bromide at $\mathrm{pH} 9.2$ [89]. Detection limits were about $110 \mu \mathrm{g} / \mathrm{ml}$, corresponding to $150-320 \mu \mathrm{M}$ [89]. Following similar strategy, sugar acids (gluconic, galacturonic and glucuronic acids) were analyzed by CE using indirect UV detection [90]. In that work [90], various BGEs containing p-hydroxybenzoic acid, sorbic acid, potassium hydrogen phthalate, protocatechuic acid, $\alpha$-resorcylic acid and $\beta$-resorcylic acid were compared. The choice between these electrolytes was made on the basis of studies of electrophoretic mobility and absorbance values at wavelengths of the CE system, giving $\beta$-resorcylic the best results. Best separation of the 3 acids was achieved in $8 \mathrm{~min}$, for an electrolyte consisting of $5 \mathrm{mM} \beta$-resorcylic acid, $1 \mathrm{mM}$ tetradecyltrimethylammonium hydroxide flow modifier at $\mathrm{pH} 3.0$ with indirect detection at $214 \mathrm{~nm}$. The proposed method was applied to must and wine samples. Also using indirect UV detection, five carbohydrates (sucrose, maltotriose, maltose, glucose and fructose) were analyzed by CE [91]. 
The method required 1-naphthylacetic acid as BGE at pH 12.5, indirect UV detection at $222 \mathrm{~nm}$, with a capillary of $75 \mu \mathrm{m} \times 120 \mathrm{~cm}$ and a voltage of $25 \mathrm{kV}$. The method was used to determine carbohydrates during the brewing process of a non-alcoholic beer and also to analyze the carbohydrate content of dietetic fruit juices and chocolate [91].

$\mathrm{CE}$ analysis of carbohydrates at high $\mathrm{pH}$ with electrochemical detection, is an interesting approach because the hydroxyl groups of carbohydrates can be partially ionized, which in turn permits their effective separation in CZE mode. The separated species can be sensitively monitored by electrochemical detection on e.g., a gold or copper electrode. The use of a $\mathrm{Cu}$ electrode in strongly alkaline solution for carbohydrate analysis has shown to be sensitive and convenient. Thus, a CE method with electrochemical detection was developed to determine fructose, glucose, maltose and sucrose levels in rice flour [92]. The working electrode was a Cu-disc electrode (diameter $140 \mu \mathrm{m}$ ), operated in a wall-jet configuration. Baseline separation of fructose, glucose, maltose and sucrose in a $50 \mathrm{mM} \mathrm{NaOH}$ buffer could be achieved within 15 min with detection limits of $1.3 \times 10^{-7}, 6.0 \mathrm{x}$

$10^{-7}, 1.4 \times 10^{-6}$ and $9.0 \times 10^{-7} \mathrm{~g} / \mathrm{l}$, respectively. The assay was used to monitor changes in sugar contents during storage of rice flour; glucose and fructose levels increased, whereas those of sucrose and maltose decreased [92]. Also CE with amperometric detection (Cu electrode) was used to determine sugar contents in soft drinks [93]. Namely, sucrose, glucose, and fructose were separated within $330 \mathrm{~s}$ in an $8.5 \mathrm{~cm}$ length capillary at a separation voltage of $1000 \mathrm{~V}$ using a 50 $\mathrm{mM} \mathrm{NaOH}$ running buffer at $\mathrm{pH} 12.7$.

\section{DNAs.}

Nowadays, there is an increasing interest among food analysts regarding the use of DNA as analytical-target. This is due to DNA sequences are extraordinarily suitable to provide highly 
specific biological information at every taxonomic level. Besides, DNA techniques have evolved considerably in recent years. Thus, the development of polymerase chain reaction (PCR) as an analytical tool has been pivotal in this field since its application can improve in a huge extent the sensitivity of any analytical method based on DNA detection. This point is paramount when using PCR for analytical purposes, since it allows exponential amplification of selected DNA sequences with high degrees of sensitivity and specificity. The availability of thermocyclers and thermostable polymerases has made it possible to automate the whole process and, as a result, to popularize this technology in food research, giving rise to a large number of molecular techniques. The combined use of molecular techniques together with CE has, therefore, brought about an impressive analytical procedure that combines the selectivity and the sensitivity increases provided by any molecular technique with the speed of analysis, resolving power and low sample requirements of CE techniques. Thus, PCR-based techniques combined with CE separation have demonstrated to be a powerful analytical method for: (i) detection of genetically modified organisms, also called transgenic foods [95,96]; (ii) detection of food-borne pathogens and food-spoilage bacteria [97101]; and (iii) species identification [102,103], when e.g., fraudulent substitution, addition or contamination are suspected in foodstuffs. These applications include analysis of transgenic maize [95,96], detection of lactic acid bacteria [97], detection of spoilage bacterium Alicyclobacillus acidoterrrestris [98], detection of toxigenic fungi from dry cured meat (MEKC was also used to study secondary metabolites produced by fungal strains) [99], detection of food-borne pathogens, mainly Salmonella [100,101], identification of porcine, caprine, and bovine meats [102], and identification of molecular markers of Glu-1 genes in wheat allowing selection of wheat genotypes of higher breadmaking quality [103]. These applications have important health, religious and/or economical implications for consumers, the food industry and regulatory agencies.

In this sense, our group has demonstrated for the first time the possibilities of the combined use of PCR and capillary gel electrophoresis with laser induced fluorescence (CGE-LIF) to detect 
genetically modified organisms (transgenic foods) [4,5]. Recently, a new PCR-CGE-LIF approach to quantitatively determine the content of genetically modified $\mathrm{Bt}$ maize in foods was developed [95]. Also, a new multiplex-PCR-CGE-LIF procedure was shown to be useful for the sensitive and simultaneous analysis of five transgenic maizes in a singe run [96]. We have also developed a new multiplex-PCR-CGE-LIF procedure for the detection and differentiation of several food-spoilage lactic acid bacteria [97]. Namely, the PCR-CGE-LIF protocol allows the simultaneous detection and differentiation of the genera Leuconostoc and Carnobacterium, the nonmotile group of species within the genus Carnobacterium, and the three species of the group C. divergens, C. gallinarum, and C. maltaromicum [97]. Moreover, we have also developed a new multiplex PCR-CGE-LIF method for the simultaneous and sensitive detection of three food-borne pathogens (namely, Staphylococcus aureus, Listeria monocytogenes, and Salmonella spp.) [100]. In this sense, one of the main advantages of PCR-CGE-LIF compared to conventional microbiological techniques is that PCR-CGE-LIF makes possible to obtain fast, sensitive, specific and inexpensive analysis of microorganisms at the molecular/genetic level.

\section{VITAMINS.}

One of the main applications of CE for vitamins [23,104-107] has been the determination of flavins $[104,105]$, due to their native fluorescence and good solubility in water. Thus, an inexpensive method for the routine analysis of riboflavin in beer by MEKC using blue light emitting diode induced fluorescence detection was described by Su et al [104]. The detection limit was down to 1 $\mathrm{ng} / \mathrm{ml}$, allowing the determination of riboflavin in 12 different types of commercial beer at concentrations ranging from 130 to $280 \mathrm{ng} / \mathrm{mL}$. Also, riboflavin was determined in wines using CE-LIF [105]. In that work [105], sample-preparation required only dilution and filtration of wines, obtaining a limit of detection of riboflavin of $0.5 \mathrm{ng} / \mathrm{ml}$. The concentrations of riboflavin ranged 
from 69 to $151 \mathrm{ng} / \mathrm{ml}$ for white, rose and red wines. This type of analytical methods can satisfy the demands for accurate and sensitive detection with minimal sample preparation and cleanup.

Vitamin B6, also known as pyridoxine, is a water-soluble vitamin that helps brain function and helps the body convert protein to energy. Some research has shown that vitamin B6 works with folic acid and vitamin B12 to reduce levels of the amino acid homocysteine in the blood. Elevated homocysteine levels can increase a person's risk of heart attack. A CE-UV method using an acidic carrier electrolyte based on phosphoric acid and direct UV detection at $195 \mathrm{~nm}$ was found to be the best solution for the determination of vitamin B6 in infusion solutions [23]. Another B-vitamin, the vitamin B5, also called pantothenic acid, is used by the body to break down carbohydrates, proteins and fats for energy. In a work by Sadecka et al [106], capillary isotachophoresis was investigated for the quantification of pantothenic acid in non-fortified and fortified milk-based samples (milk infant formulas) and fortified corn flakes samples. Sample preparation consisted of deproteination with acetic acid followed by centrifugation and filtration. The leading electrolyte was $10 \mathrm{mM} \mathrm{HCl}$ including $0.1 \%$ polyvinylpyrrolidone adjusted with histidine to $\mathrm{pH}$ 6.0. The terminating electrolyte was $5 \mathrm{mM}$ 4-morpholineethanesulfonic acid adjusted with tris(hydroxymethyl)aminomethane to $\mathrm{pH}$ 6.2. The limit of quantification was calculated to be $1.6 \mathrm{mg} / \mathrm{kg}$. It is concluded that the minimal sample pretreatment and relatively low running costs make isotachophoresis a good alternative to existing methods for quantification of pantothenic acid.

Vitamin C, also known as ascorbic acid, is a water-soluble vitamin that helps to heal wounds, prevent cell damage and strengthen the immune system. It also helps the body to absorb iron. Recent research has indicated that vitamin C may be associated with delayed aging and disease prevention by destroying free radicals, i.e., the molecules associated with aging and cell damage. A CE method with diode array detection was used for the simultaneous analysis of L-ascorbic acid (L-AA) and D-isoascorbic acid (D-IAA) in fruit juices [107]. The limit of detection was 1.6 and 1.1 
mg/l for L-AA and D-IAA, respectively. Analysis of the L-AA and D-IAA contents in 26 commercial apricot juices (5 organic, 5 integrated, 16 conventional) showed that L-AA was not present in 4 of the apricot juices (2 organic and 2 integrated), while the overall range of L-AA found in the other juices was between 8 and $486 \mathrm{mg} / \mathrm{l}$. As expected, D-IAA was not detected in any juice since it is a food additive used as antioxidant that does not naturally exist in foods [107].

\section{SMALL ORGANIC AND INORGANIC IONS.}

Analysis of small ions by CE is also an active area in food analysis [108-119]. In general, two main problems have to be solved when analyzing small ions by CE. The first one is the poor (or null) UV absorptivity of many of these species, and the second one refers to the peak broadening induced by electrophoretic dispersion that in many cases ruins the CE separation of these small ions. Although it is clear that in some cases CE with direct UV detection can be applied for analyzing small ions, authors have focused on solving the sensitivity problem. Some solutions include derivatization prior to UV detection, use of indirect detection, or use of other detectors different from UV, as for instance conductivity [118] or MS [119].

Thus, coelectroosmotic CE with direct UV detection at $210 \mathrm{~nm}$ was applied to analyze 19 lowmolecular-mass organic acids in beer samples [109]. The analyzed acids were ketoglutaric, fumaric, malic, mesaconic, oxalic, pyroglutamic, pyruvic, sorbic, 4-aminobenzoic, benzoic, pcoumaric, ferulic, phthalic, gallic, 4-hydroxybenzoic, homovanillic, protocatechuic, sinapinic and syringic [109]. Direct UV detection at $200 \mathrm{~nm}$ was also used by Galli and Barbas [110] to analyze short-chain organic acids in coffee. In that work [110], 17 short-chain organic acids (oxalic, formic, fumaric, mesaconic, succinic, maleic, malic, isocitric, citric, acetic, citraconic, glycolic, propionic, lactic, furanoic, pyroglutamic, quinic acids) plus nitrate were separated, identified and measured. Results in coffees with different industrial treatment allow the detection of important differences in 
the organic acid profile [110]. Similar approach was used by Buiarelli et al [111] to analyze citric, orotic, uric and hippuric acids in whey, concluding that CE is a quick and easy technique for determination of milk whey acids. CE-UV also provided the simultaneous determination of arsenite, arsenate, monomethylarsonic acid, dimethylarsinic acid, selenate, selenite, selenocystine, selenomethionine and selenocystamine at $195 \mathrm{~nm}$ [112]. In this case, a $15 \mathrm{mM}$ phosphate buffer at pH 10.6 was used as BGE. The method was used to determine the Se compounds in nutrition supplements and for speciation of As [112].

An interesting alternative to analyze inorganic cations by CE-UV is to complex the analytes before their detection with a chromophore. Thus, vanadium (IV) and vanadium (V) species were chelated with aminopolycarboxylic acids to form anionic complexes that were analyzed by CE-UV [113]. EDTA, diethylenetriaminepentacetic acid, nitrilotriacetic acid, and N-2hydroxyethylethlendiaminetriacetic acid were investigated as both ligand and running electrolyte. Among the ligands studied, complexes of EDTA with vanadium (IV) and vanadium (V) resulted in the highest selectivity and UV response. The proposed method was applied to the determination of vanadium in groundwater spiked with vanadium (IV) and vanadium (V) [113].

Indirect UV detection is frequently applied when small organic and inorganic ions have to be analyzed by CE [114-117]. In this case a strong chromophore is added to the BGE and analytes are detected as negative peaks. An additional problem of this type of detection (apart of the peak broadening mentioned above), is that all compounds passing through the detector will give a signal, making very difficult the analysis. This procedure has been applied to analyze organic acids and inorganic anions in orange juice, red and white wine samples [114]. In this case [114], a new procedure was developed based on a new BGE system containing $3 \mathrm{mM}$ 1,3,5-benzenetricarboxylic acid, $15 \mathrm{mM}$ tris-(hydroxymethyl)-aminomethane and $1.5 \mathrm{mM}$ tetraethylenepentamine at $\mathrm{pH}$ 8.4. Baseline separation of anions commonly found in orange juice and wine could be achieved in less 
than 14 min with indirect UV detection at $240 \mathrm{~nm}$ [114]. Following similar principle, the 6 main organic acids in wine (tartaric, malic, citric, succinic, acetic and lactic acids) were analyzed by CE with indirect UV detection using 2,6-pyridinedicarboxylic acid as BGE [115]. Also, fluoride, chloride, bromide, nitrite, nitrate, sulfate and phosphate were detected in drinking water by using CE with indirect UV detection [116]. In this case, $0.10 \mathrm{mM}$ benzethonium chloride was used as EOF modifier and $25 \mathrm{mM}$ sodium thiosulfate as BGE at pH 5.00. A CE method with indirect UV detection was recently developed allowing the separation of the organic acids involved in the malolactic fermentation of wine [117]. Using a running electrolyte consisting of $35 \%(\mathrm{v} / \mathrm{v})$ methanol in a solution of $22 \mathrm{mM}$ benzoic acid at $\mathrm{pH} 6.10$ adjusted with $1.0 \mathrm{M}$ TRIS-base buffer, the separation of tartaric, malic, succinic, acetic, and lactic acids was feasible in less than $210 \mathrm{~s}$. Application of the method to the quantification of the above-mentioned organic acids in Italian red wine samples was demonstrated [117].

\section{TOXINS, CONTAMINANTS, PESTICIDES AND RESIDUES.}

Food safety is the first concern for food analysts. Foods must be free of toxins, pesticides, antibiotics, bacteria, etc, that even at very low concentrations can be dangerous for the human health. To ensure human food safety, maximum residue limits (MRLs) for many of these residues in food products have been defined. Analytical methods need to be developed to confirm the presence of these compounds below the MRL level. Therefore, fast and sensitive analytical procedures are required by the analytical laboratories to face this important demand. In this sense, CE has mostly been applied to detect different type of pesticides in foods [120-131], although some other interesting applications as detection of veterinary drugs [132-134], toxins [135-137] and bacteria $[138,139]$ have also been carried out by CE. 
Since some pesticides can be dangerous even at trace levels, sensitivity is an important issue to address when analyzing these compounds. Our group has developed new CE procedures for highly sensitive detection of pesticides in foods [120-122]. In these works, a combination of chemometrics, SPE or SPME, on-line preconcentration strategies and CE with UV [121] or MS detection [120,122] has been applied. Using this combined approach it was possible to detect pesticides in different beverages below their MRLs values, achieving limits of detection of a few $\mu \mathrm{g} / \mathrm{l}$ in real food samples.

An alternative procedure to reach high sensitivity is to use laser induced fluorescence (LIF) detection with CE. Thus, aminated pesticides and metabolites were analyzed by CE-LIF using precolumn derivatization with fluorescein isothiocyanate (FITC) [123]. Different variables affecting the derivatization reaction ( $\mathrm{pH}$, FITC concentration, reaction time and temperature) and those related with the separation itself (buffer concentration, addition of various organic modifiers, $\mathrm{pH}$, applied voltage and injection time) were studied. The limit of detection obtained under optimum CE-LIF conditions was between 0.45 and $3.48 \mu \mathrm{g} / \mathrm{l}$ [123].

As mentioned above, a useful strategy to sensitively analyze pesticides in foods is to develop adequate preconcentration strategies before their CE detection. Thus, carbendazim and thiabendazole (two fungicides) could be determined by CE in citrus fruits at levels 10 times lower than MRL established by the EU [125]. To reach these levels, a sample clean-up procedure was developed consisting of fruit homogenization, extraction with ethyl acetate and purification through a series of separatory-funnel and acid-base partitions [125]. Following this idea (i.e., to increase CE sensitivity), different on-line preconcentration methods were studied for multiresidue analysis of pesticides by MEKC [126], including sweeping, stacking with reverse migration of micelles (SRMM) and a modification of SRMM. Nine pesticides (ametryn, carbendazim, atrazine, propoxur, propazine, linuron, diuron, simazine and carbaryl) were mixed and used to spike samples of 
drinking water and carrots, which were then treated by the proposed strategies. A pH 2.5 electrolyte system consisting of $0.02 \mathrm{M}$ phosphate buffer, $0.025 \mathrm{M}$ SDS and 10\% methanol was used for separation of the pesticides. Using the preconcentration strategies, improved limits of detection were achieved for the pesticides under investigation (2-46 $\mu \mathrm{g} / \mathrm{l}$; enrichment factors 3-18-folds) [126]. In a different work [127], a new sorbent for SPE of polar pesticides (phenoxy acids, triazines, ureas, oxime carbamates and carbamates) has been evaluated, showing its usefulness through MEKC determination of these pesticides in tap and river water samples [127]. Analysis of pesticides in foods by using CE-MS has shown to be an interesting alternative in order to improve both the sensitivity and specificity of the analysis [120,122,129-131].

Antibiotics and other veterinary drugs are extensively applied in veterinary medicine for the treatment of various bacterial infections. Because of their use in food producing animals, the risk of occurrence of unwanted residues in edible products exists. In this regard, CE-UV has been proposed for the quantitative determination of these residues from poultry and porcine tissues [132]. Namely, eight of the most frequently used antibiotics and nifursol, which is routinely used as poultry coccidiostat, were analyzed. CE-UV permitted analyzing these substances from muscle, liver, kidney and skin with fat after a simple extraction with acetonitrile or ethyl acetate under basic conditions. The CE-UV method was capable of detecting drug residues in these tissues at level below $20 \mu \mathrm{g} / \mathrm{kg}$.

Sulfonamide is an antibacterial used as veterinary drug for the treatment of infections. Sulfonamide detection in foods is an important concern, due to the possibility of risk to human health (e.g., resistance development, toxicity). A new CE method with SPE was developed for the quantitative determination of eight commonly used sulfonamides (sulfamethazine, sulfamerazine, sulfadiazine, sulfadimethoxine, sulfamonomethoxine, sulfaphenazole, sulfaquinoaline and sulfisoxazole) in meat 
samples [134]. The detection limits of each sulfonamide ranged from 5 to $10 \mu \mathrm{g} / \mathrm{kg}$. The sensitivity of this newly developed method allowed the determination of the sulfonamides at a residue level far below the MRL established by the EU [134].

Detection of different toxins and toxic compounds in foods can also be carried out by using capillary electromigration methods. Thus, nitrosamines are considered human carcinogens and they could be formed in cured meats because meats contain amines and sodium nitrite (a source of nitrosating agents) that is added as a preservative. A new methodology for extraction, preconcentration and MEKC analysis of nitrosamines in meat derived products was developed, allowing the detection of these compounds at trace levels in preserved sausages [135]. CE has also been used to analyze mycotoxin moniliformin in corn [136] and organotin compounds [137].

The usefulness of CE with UV detection has also been demonstrated for the identification and quantitation of bacterial contamination in food samples [138,139]. Differences in the surface charges of bacteria were exploited for their separation by CE. In these works, separation of Escherichia coli, Proteus vulgaris, Bacillus cereus and Pseudomonas fluorescens [138], as well as separation of Yersinia enterocolitica, Leconostoc mesenteroides, Salmonella enteriditis, Listeria monocitogenes, Escherichia coli, Lactobacillus plantarum, Staphylococcus Aureus and Enterococcus faecium [139] were achieved by CE-UV. The usefulness of CE-UV was demonstrated analyzing these bacteria in different foods including corn flakes, juice, baby foods and frankfurters [139]. These procedures can be a good complement to the aforementioned CGE works based on the use of PCR-amplified DNA from these bacteria [100,101].

\section{FOOD ADDITIVES.}


Food additives are substances added to food to preserve it or to improve its flavor and appearance. Although some additives have been used for centuries (vinegar, salt, etc), with the advent of processed foods in the second half of the 20th century, many more additives have begun to be used. The appearance of these new additives, of both natural and artificial origin, has made necessary the development of new analytical procedures able to characterize them. In this sense, capillary electromigration methods can play an important role in this type of determinations, including the analysis of food colorants [140-145], sweeteners [146], and preservatives [147,148].

Analysis of colorants by CE is the most usual application of this technique in food additives [140145]. Colorants are usually added to various commercial food products in order to increase its attraction and achieve their desired color appearance. Several food colorants, whether synthetic or natural, have been permitted to be used as food additives. The allowable amount of synthetic colorants, however, is strictly limited because of their potential toxic nature. Therefore, the detection and measurement of colorants in foods are relatively important for health issue reasons. Thus, a natural colorant (carminic acid) and seven synthetic food colorants (tartrazine, fast green FCF, brilliant blue FCF, allura red AC, indigo carmine, sunset yellow FCF, and new coccine) were analyzed in milk beverages using CE [140]. The CE method employed a $\mathrm{pH} 10.0$ running buffer containing $7.0 \mathrm{mM} \beta$-cyclodextrin, and allowed the separation of the the colorants with baseline resolution within 9 min. In order to reduce the matrix interference resulting from the constituents of milk, a suitable polyamide column SPE was also investigated for milk sample pretreatment. The combination SPE-CE was able to determine successfully without matrix interference the content of these colorant additives in commercial milk beverages with detection limits lower than $0.5 \mu \mathrm{g} / \mathrm{ml}$ [140]. Similar approach, i.e. SPE-CE, was used to determine different food dyes (tartrazine, sunset yellow, carmoisine, ponceau $4 \mathrm{R}$, allura red, brilliant black, amaranth, green $\mathrm{S}$, brilliant blue, patent blue, erythrosine and indigo carmine) in alcoholic beverages, including beer, fruit liqueur, port, 
vodka cocktails and wine [141]. Also, SPE-CE was used to analyze the dyes brilliant blue and azorubine in red wines [142].

The development of MEKC [143,144] and MEEKC [145] procedures has shown to be a good alternative to CZE methods to analyze food dyes since they could skip the sample preparation step. Thus, Huang et al [145] have analyzed eight food colorants (tartrazine, fast green FCF, brilliant blue FCF, allura red AC, indigo carmine, sunset yellow FCF, new coccine, and carminic acid) in three different flavored soft drinks and three different flavors popsicles. According to these authors [145], the MEEKC method has a higher separation efficiency and similar detection limit when compared to conventional CZE. Furthermore, the sample pretreatment is rarely needed when this MEEKC technique is used to analyze colorants in food products, whereas a suitable sample pretreatment (for example SPE) had to be employed prior to CE separation in order to eliminate matrix interferences resulting from the constituents of the food sample [145].

Other applications of CE to analyze food additives include the determination of the artificial sweetener Sucralose (R) in low-calorie soft drinks using indirect UV detection in a 3,5dinitrobenzoic acid buffer at $\mathrm{pH} 12.1$ [146]; or the use of SPE-MEEKC for simultaneous determination of 7 preservatives (methyl, ethyl, propyl and butyl parabens, sorbic acid, benzoic acid and dehydroacetic acid) in soft drinks, wines and soy sauces [147]. Also, the sensitivity enhancement derived from the combined use of isotachophoresis and capillary zone electrophoresis using a commercial instrument with two coupled capillaries was investigated by Flottmann et al [148]. As an application of this combination, sorbic and ascorbic acid were analyzed in an "alcopop"-drink at the nanomolar range [148].

\section{FOOD INTERACTIONS AND PROCESSING.}


Study of food processing and food interactions has to be addressed in food science since it can provide useful information about e.g., food quality and safety. It is evident that some industrial processes (as e.g., heating, roasting, storage, etc) can modify the chemical composition of foods, giving rise to new compounds that in some cases can be dangerous for human health. Therefore, analytical laboratories must develop suitable procedures to monitor these changes. Moreover, identification of some food compounds as "target-analytes" can allow determining food quality (and in some case health-risks) linked to processing effects, storage, cooking, aging, etc. Additionally, interactions among food ingredients (and interactions among food compounds with drugs) are also important issues not only for food scientists. Generally speaking, CE has demonstrated that can provide interesting information on the effect of industrial processing on foods [25,110,149-150], storage [92], cooking [151,152] as well as on interactions between different food compounds [153-155]. Some of these applications are next discussed.

Since the fruit juice industry has become one of the most important agricultural businesses in the world, quality modifications of juices induced by processing is an important issue that demands the development of new analytical procedures. In this sense, our group has demonstrated that the use of chiral amino acids content and stepwise discriminant analysis can allow classifying commercial orange juices that have been submitted to different processing (i.e., nectars, orange juices reconstituted from concentrates, and pasteurized orange juices not from concentrates) [25]. MEKCLIF and $\beta$-cyclodextrin was used to determine L- and D-amino acids previously derivatized with FITC, concluding that chiral MEKC-LIF analysis of amino acids and stepwise discriminant analysis can be used as a consistent procedure to classify commercial orange juices providing useful information about their quality and processing [25]. 
A CE method was developed to detect 17 short-chain organic acids (oxalic, formic, fumaric, mesaconic, succinic, maleic, malic, isocitric, citric, acetic, citraconic, glycolic, propionic, lactic, furanoic, pyroglutamic, quinic acids) plus nitrate in coffee [110]. Differences in the organic acid profile by CE were observed for coffees with different industrial treatments [110]. Also, a new CE method was established for the quantitative determination of furosine in dairy products [149]. It has been demonstrated that furosine is a good indicator of the extent of the early Maillard reaction related to the type and intensity of the food processing conditions, as well as to the storage conditions, and can be used as a suitable indicator of the quality of dairy products.

An example of the compositional changes induced by processing was provided by Sung and Li [150]. Liquorice is usually processed using a roasting procedure that can modify its chemical composition. To test this hypothesis, liquorice root samples were roasted under various conditions and their composition analyzed by CE with a running buffer composed of $50 \mathrm{mM}$ sodium tetraborate at pH 9.01 containing $5 \mathrm{mM} \beta$-cyclodextrin. Thermal decomposition of glycyrrhizin, a major component of liquorice, was observed and results suggested a conversion of glycyrrhizin to glycyrrhetinic acid [150].

A CE method with electrochemical detection was developed for measurement of fructose, maltose, glucose and sucrose levels during storage of rice flour [92]. From the assay it was concluded that glucose and fructose levels increased, whereas those of sucrose and maltose decreased during storage [92].

Heterocyclic aromatic amines (HAA) are mutagenic, carcinogenic compounds formed at low levels in protein-rich foods during cooking. Due to the low concentration of HAA and the complexity of these cooked foods, sensitive and selective analytical methods are required for their quantification. 
Viberg et al [151] developed a miniaturized technique for analysis and detection of HAA using solid phase extraction (SPE) coupled on-line (in-capillary) to CE separation with nanospray electrospray ionization (nESI) MS detection. SPE was performed on a packed bed of C18 particles inside the CE capillary, which minimized the dead volume. The on-line coupling of SPE, CE and nESI-MS reduced the time for extraction and identification to less than $30 \mathrm{~min}$. The new method exhibited a short analysis time, and low sample and solvent consumption. Using the method, HAA were detected in standard solutions at 12-17 fmol injections.

Acrylamide is a toxic compound to the nervous system of both animals and humans. The interest in the determination of acrylamide has increased considerably since it was known that the amount of this compound could increase in heat treated carbohydrate-rich foods. A MEEKC method using 0.8\% n-amyl alcohol, 3.3\% SDS, 6.6\% 1-butanol and 89.3\% $40 \mathrm{mM}$ phosphate buffer at $\mathrm{pH} 6.5$ was developed to detect acrylamide [152]. Suitability of the MEEKC method was demonstrated by analyzing levels of acrylamide in samples of home made French fries [152].

Different interactions between food ingredients have been investigated by CE methods. The reason is that these interactions (mainly involving biopolymers) can have many potential applications in pharmaceutical, cosmetic, nutraceutical, and functional food industries as well as in food processing. Thus, the bindings of beta-lactoglobulin to retinoic acid [153] and pectin [154] have been studied by affinity-CE and by frontal analysis continuous-CE, respectively. In a different work, molecular associations of wheat glutenins and carbohydrates were also monitored by CZE [155]. These associations are important in bread making and are believed to contribute to differences in a number of dough and baking quality characteristics [155].

\section{CHIRAL ANALYSIS OF FOOD COMPOUNDS.}


Enantioselective separations can be used in food and beverage analysis for [156] (a) identifying adulterated foods and beverages, (b) evaluation and identification of age, treatment and storage effects, (c) more exact control and monitoring of fermentation processes and products, (d) more exact evaluation of some flavor and fragrance components, (e) fingerprinting complex mixtures, (f) analysis of chiral metabolites of many chiral and prochiral constituents of foods and beverages, (g) 50\% less material (e.g., flavors, preservatives, additives, etc.) can be used in some cases, (h) decreasing environmental persistence of some compounds. In this regard, CE is very well suited for chiral analysis since this technique provides fast and efficient separations. Moreover, the availability of many chiral selectors and the minimum consumption of such compounds during a CE run have to be considered as an additional advantage of chiral electromigration methods. In spite of these advantages, application of chiral CE in food analysis is still at its infancy [3].

Table 3 shows the chiral-CE applications in food analysis found in the period covered by this review [24-26,157-162]. As can be seen in Table 3, cyclodextrins and their derivatives are the main chiral selectors used in CE and they have been applied to analyze different food compounds as amino acids, monoterpenes, catechins, flavanones and furanones. It is interesting to remark one of the first applications published on chiral-CE-MS in food analysis [26]. In that work from our group [26], a new chiral-CE-MS method was developed to analyze the chiral amino acids D/L-Asp, -Glu, -Ser, -Asn, -Ala, -Pro and -Arg, plus $\gamma$-aminobutyric acid in orange juices. Some of the typical limitations observed when combining ESI-MS and non-volatile chiral selectors as cyclodextrins were solved by using a physical coating of the capillary [26]. The suitability of this new chiral-CEMS procedure is demonstrated in Figure 3, showing that this chiral-CE-MS method allows detecting adulterations using as low as $0.8 \%$ (with respect to the total amino acid content) of $\mathrm{D} / \mathrm{L}$ Asp in orange juices, in which only the L-forms of the amino acids are expected to occur. 


\section{OTHER APPLICATIONS.}

Apart of the applications described above, CE methods have also been used to analyze other different compounds in foods [163-174]. Thus, capillary electromigration methods have successfully been applied for the simultaneous determination of multiple constituents in real beer samples [163,164]. In these works, alcohols, amines, amino acids, flavonoids, and purine and pyrimidine bases were analyzed by CZE-UV using a $70 \mathrm{mM}$ sodium borate solution at $\mathrm{pH} 10.25$ [163]. Alcohols, iso- $\alpha$-acids, amino acids, flavonoids, isoflavonoids, vitamins, purine and pyrimidine bases were analyzed by MEKC-UV using a $25 \mathrm{mM}$ sodium borate and $110 \mathrm{mM}$ SDS buffer at pH 10.5 [164].

MEKC-UV was compared with HPLC-UV for separation of components of vanilla extracts [165]. The MEKC method offered adequate resolution for all components within a much shorter analysis time (8 min run time +4 min rinsing) than the HPLC method (25 min run time +15 min rinsing and equilibration). However, limits of detection using MEKC were two orders of magnitude higher than using HPLC. Results obtained with the two methods did not differ for resolution of vanillin, vanillic acid, 4-hydroxybenzoic acid and 4-hydroxybenzaldehyde, concluding that MEKC is a good alternative for the determination of vanilla compounds in commercial preparations [165].

The glycoalkaloid content of transgenic potatoes was evaluated by Biano et al [166] using an optimized method based on nonaqueous CE coupled on-line with electrospray ionization-mass spectrometry. The potato samples consisted of tubers from three lines of modified plants (i.e., resistant, intermediate and susceptible to infection by potato virus Y). The main glycoalkaloids were confirmed to be $\alpha$-solanine and $\alpha$-chaconine. Total glycoalkaloids content was nearly doubled in peel samples of resistant compared to control lines, and these levels were lower than the limit recommended for food safety, i.e. 20-60 mg of total glycoalkaloids per $100 \mathrm{~g}$ fresh weight. 
Moreover, it was established that tubers produced by virus-resistant clones are substantially equivalent in glycoalkaloid contents to those produced by conventional potato varieties [166].

A CE method with indirect photometric detection was developed to identify and quantify myoinositol phosphates in foods [167]. These compounds seem to have some benefits to human health including preventive, therapeutic action as anticancer agents, antioxidants and inhibitors of the crystallization of pathological calcium salts such as renal calculi and tissue calcifications. A flowinjection system including a micro-SPE column containing an anionic exchange resin was used for the extraction of the myo-inositol phosphates. The flow injection system was automatically coupled to the CE instrument via a mechanical interface. The proposed method was applied to a variety of food samples observing that the content of myo-inositol hexakisphosphate in nuts was almost three times higher than in legumes [167].

Some other interesting applications of CE in food analysis include authenticity studies of cheese [168], determination of taurine in Lycium Barbarum L., beverages and milk powder [169], separation of conjugated linoleic acid isomers and parinaric fatty acid isomers [170], determination of phytohormones in tomato [171] and coconut [172], separation and determination of active components (anthraquinone derivatives) in rhubarb [173] and separation and analysis of the major constituents (eugenol and $\beta$-caryophyllene) of cloves [174].

\section{MICROCHIPS AND OTHER FUTURE TRENDS IN FOOD ANALYSIS.}

Despite the many applications of CE in food science shown in this review, some CE limitations have still to be improved. Thus, although the volumes of sample usually consumed per analysis are a few nanoliters, the sensitivity in terms of concentration is not very high, what precludes the use of CE for determination of trace compounds. To enhance the sensitivity different strategies have been 
applied as for example, sample preconcentration, stacking procedures or more sensitive detection systems (e.g., laser induced fluorescence, amperometric, MS detection). It is expected that application of these strategies (and their combination [120-122]) will continue growing in food analysis. Also, the reproducibility of quantitative analyses by CE is frequently low since there are many factors that can influence the sample volume injected (e.g., temperature and salts content of sample solution, capillary status, etc). Some technical or methodological development is expected to improve this general limitation of CE methods. The adsorption of analytes bearing a highly positive electrical charge onto the negatively charged capillary wall is also a frequent problem that can ruin the separation performance. To solve this problem several strategies will keep going, among them the coating of the inner wall with a polymeric film seems to render to the date the best results [33].

It can be expected that many of the new CE instrumental and methodological developments will find application in food analysis in the non-distant future. This idea can be easily understood considering the example of microchips and their recent applications in food analysis [98,175-185] (see Table 4). Thus, as can be deduced from Table 4, microchips have already been applied in food analysis to differentiate species [175], to detect food spoilage bacteria [98], to detect GMOs [176,184], and to analyze small organic and inorganic compounds such as amino acids, sugars, etc [177-183]. Moreover, different detection schemes have been developed to be used together with microchips including LIF [98,175,176,184], conductivity [178-181], amperometric [182,183] and MS detectors [186]. This will make possible to address and solve an even wider number of problems in food science. As an example, Figure 4 shows the chip-CGE-LIF development used to detect GMOs through analysis of their DNA. It is expected that the low cost and highthroughput of microchips will generalize their use in food analysis in a short time. 
Other interesting approach is the construction of CE-based-sensors for the detection of electroactive analytes [187], that can see a huge application within the nutraceuticals area (e.g., antioxidants). The application of CE to the analysis of traces of allergens, toxins, antibiotics and/or pesticides can provide important results by combining CE with immunological techniques and more sensitive spectroscopic procedures (e.g., immunofluorescence). The combined use of CE and immunological techniques or PCR can be applicable for detection of microorganisms in foods. Other future aspect that needs to be mentioned is the increase in selectivity and analyte information that can be obtained by using CE coupled to spectroscopic techniques such as NMR [188]. In this sense, although CE-MS has already been used for a good number of applications in food science [8], it must still be considered a new technique in this application field. Moreover, the combined use of chiral analysis plus CE (or CE-MS [26]) is a very powerful analytical approach whose applicability is still at its infancy in food analysis. Similar concept can be applied to CEC (and CEC-MS) techniques that have been very seldom applied in food analysis so far.

\section{ACKNOWLEDGMENT}

A.C. would like to thank Susana Caballero for her great work with literature. This work was supported by Projects AGL2002-04621-C02-02 (CICYT) and 2004IT0037 (CSIC-CNR). 


\section{REFERENCES}

[1] Frazier, R.A., Papadopoulou, A., Electrophoresis 2003, 24, 4095-4105.

[2] Hernández-Borges, J., Frías-García, S., Cifuentes, A., Rodríguez-Delgado, M. A., J. Sep. Sci. 2004, 27, 947-963.

[3] Simó, C., Barbas, C., Cifuentes, A., Electrophoresis 2003, 24, 2431- 2441.

[4] García-Cañas,V., Cifuentes, A., González, R., Crit. Rev. Food Sci. 2004, 44, 425-436.

[5] García-Cañas, V., González, R., Cifuentes, A., Trac-Trend Anal. Chem. 2004, 23, 637-643.

[6] Herrero, M., Ibáñez, E., Cifuentes, A., J. Sep. Sci. 2005, 28, 883-897.

[7] Cortacero-Ramirez, S., Hernainz-Bermudez de Castro, M., Segura-Carretero, A., CrucesBlanco, C., et al, TRAC-Trends Anal. Chem. 2003, 22, 440-445.

[8] Simó, C., Barbas, C., Cifuentes, A., Electrophoresis 2005, 26, 1306-1318.

[9] Berrada, H., Font, G., Molto, J.C., Crit. Rev. Anal. Chem. 2003, 33, 19-41.

[10] Galli,V., Garcia, A., Saavedra, L., Barbas, C., Electrophoresis 2003, 24, 1951-1981.

[11] Flurer, C.L., Electrophoresis 2003, 24, 4116-4127. 
[12] Poinsot, V., Bayle, C., Couderc, F., Electrophoresis 2003, 24, 4047-4062.

[13] Martinez-Montero, C., Rodriguez-Dodero, M.C., Guillen-Sanchez, D.A., Barroso, C. G., Chromatographia 2004, 59, 15-30.

[14] Blake, C., Food Sci. Tech. 2004, 18, 25-27.

[15] Barbas, C., Saavedra, L., J. Sep. Sci. 2002, 25, 1190-1196.

[16] Juan-García, A., Font, G., Picó, Y., J. Sep. Sci. 2005, 28, 793-812.

[17] Kvasnicka F., J. Sep. Sci. 2005, 28, 813-825.

[18] Vallejo-Cordoba, B., González-Córdova, A., Mazorra-Manzano, M.A., Rodríguez-Ramírez, R., J. Sep. Sci. 2005, 28, 826- 836.

[19] Castañeda, G., Rodríguez-Flores, J., Ríos, A., J. Sep. Sci. 2005, 28, 915 - 924.

[20] Chen, X., Zhang, J., Zhai, H., Chen, X., Hu, Z., Food Chem. 2005, 92, 381-386.

[21] Fujiya, N. M., Tavares, M. F.M., J. Sep. Sci. 2003, 26, 562-568.

[22] Komarova, N., Kamentsev, J.S., Solomonova, A.P., Anufrieva, R.M., J. Chromatogr. B 2004, 800, 135-143. 
[23] Klampfl, C.W., Vo, T.D.T., J. Chromatogr.B 2003, 26, 2783-2795.

[24] Simo, C., Barbas, C., Cifuentes, A., J. Agric.Food Chem. 2002, 50, 5288-5293.

[25] Simó, C., Martín-Álvarez, P.J., Barbas, C., Cifuentes, A., Electrophoresis 2004, 25, 28852891.

[26] Simó, C., Rizzi, A., Barbas, C., Cifuentes, A., Electrophoresis 2005, 26, 2885-2891.

[27] Lange, J., Thomas, K., Wittmann, C., J. Chromatogr. B 2002, 779, 229-239.

[28] Sun, X. H., Yang, X. R., Wang, E.K., J. Chromatogr. A 2003, 1005, 189-195.

[29] Wang, Q., Yu, H., Li, H., Ding, F., et al., Food Chem. 2003, 83, 311-317.

[30] Cinquina, A.L., Longo, F., Cali, A., de Santis, L., et al., J. Chromatogr. A 2004, 1032, 79-85.

[31] Kalac, P., Krizek, M., Pelikanova, T., Langova, M., et al, Food Chem. 2005, 90, 561-564.

[32] Santos, B., Simonet, B.M., Rios, A., Valcarcel, M., Electrophoresis 2004, 25, 3231-3236.

[33] González, N., Elvira, C., San Roman, J., Cifuentes A., J. Chromatogr. A 2003, 1012, 95-101

[34] Ortega, N., Albillos, S.M., Busto, M.D., Food Control. 2003, 14, 307-314.

[35] Miralles, B., Amigo, L., Ramos, M., Recio, I., Milchwissenschaft. 2003, 58, 412-415. 
[36] Miralles, B., Ramos, M., Amigo, L., J. Dairy Sci. 2003, 86, 2813-2817.

[37] Pellegrino, L., Tirelli, A., de Noni, I., Resmini, P., Sci. Tec. Lat. Cas. 2003, 54, 321- 333.

[38] Recio, I., Garcia-Risco, M.R., Amigo, L., Molina, E., et al, J. Dairy Sci. 2004, 87, 1595-1600.

[39] Civardi, G., Curadi, M.C., Orlandi, M., Cattaneo, T.M.P., et al Milchwissenschaft. 2002, 57, 515- 517.

[40] Veledo, M. T., Frutos, M., Diez-Masa, J.C., J. Sep. Sci. 2005, 28, 935-940.

[41] Veledo, M. T., Frutos, M., Diez-Masa, J.C., J. Sep. Sci. 2005, 28, 941-947.

[42] Bean, S.R., Tilley, M., Cereal Chem. 2003, 80, 505-510.

[43] Schober, T.J., Kuhn, M., Eur. Food Res. Tech. 2003, 21, 350- 359.

[44] Yan, Y., Jiang, Y., Yu, J., Cai, M., Hu, Y., et al, Cereal Res. Com. 2003, 31, 323-330.

[45] Bonetti, A., Marotti, I., Catizone, P., Dinelli, G., et al, J. Agric.Food Chem. 2004, 52, 40804089.

[46] Yan, Y., Jiang,Y., Sun, M., Yu, J., et al, Cereal Chem. 2004, 81, 561-566. 
[47] Sebastiano, R., Simo-Alfonso, E.F., Citterio, A., Ramis-Ramos, G., Electrophoresis 2004, 25, 2970- 2977.

[48] Piergiovanni, A.R., Volpe, N., Cereal Chem. 2003, 80, 269-273.

[49] Piergiovanni, A.R., Cereal Res. Com. 2004, 32, 395-402.

[50] Blanco, D., Junco, S., Exposito, Y., Gutierrez, D., J. Liq. Chromatogr. Rel. Tech. 2004, 27, 1523-1539.

[51] Arias, M., Simó, C., Ortiz, L. T., Mozos-Pascual, M., et al, Electrophoresis 2005, 26, 23512359.

[52] Simó, C., Herrero, M., Neusüß, C., Pelzing, M., et al, Electrophoresis (in press).

[53] Simó, C., Elvira, C., González, N., San Román, J., et al, Electrophoresis 2004, 25, 20562064.

[54] Simó, C., Cifuentes, A., Electrophoresis 2003, 24 , 834-842.

[55] Kristensen, L., Therkildsen, M., Ertbjerg, P., J. Agric. Food Chem. 2003, 51, 5895-5899.

[56] Wang, S.P., Huang, K.J., J. Chromatogr. A 2004, 1032, 273-279.

[57] Peng, Y., Chu, Q., Liu, F., Ye, J., J. Agric. Food Chem. 2004, 52, 153-156. 
[58] Huang, H.Y., Lien, W.C, Chiu, C.W., J. Sep. Sci. 2005, 28, 973-981.

[59] Herrero-Martinez, J.M., Rafols, C., Roses, M., Torres, J.L., et al, Electrophoresis 2003, 24, 707-713.

[60] Bednar, P., Tomassi, A.V., Presutti, C., Pavlikova, M., et al, Chromatographia 2003, 58, 283-287.

[61] Hamoudova, R., Urbanek, M., Pospisilova, M., Polasek, M., J. Chromatogr. A 2004, 1032, 281-287.

[62] Okunji, C.O., Ware, T.A., Hicks, R.P., Iwu, M.M., et al, Planta Med. 2002, 68, 440-444.

[63] Sun, X.H., Gao, C.L., Cao, W.D., Yang, X.R., et al, J. Chromatogr. A 2002, 962, 117-125.

[64] Chu, Q.C., Qu, W.Q., Peng, Y.Y., Cao, Q.H., et al, Chromatographia 2003, 58, 67-71.

[65] Mueller, A., Ganzera, M., Stuppner, H., Chromatographia 2004, 60, 193-197.

[66] Crego, A. L., Ibáñez, E., García, E., Rodríguez de Pablos, R., et al, Eur. Food Res.Technol. 2004, 219, 549-555.

[67] Herrero, M., Arráez-Román, D., Segura, A., Kenndler, E., et al. J. Chromatogr. A (in press). 
[68] Bonoli, M., Pelillo, M., Lercker, G., Chromatographia 2003, 57, 505-512.

[69] Chen, C., Liang, C., Lai, J., Tsai, Y., et al, J. Agric. Food Chem. 2003, 51, 7495-7503.

[70] Weiss, D.J., Anderton, C.R., J. Chromatogr. A 2003, 1011, 173-180.

[71] Bonoli, M., Montanucci, M., Toschi, T.G., Lercker, G., J. Chromatogr. A 2003, 1011, 163172.

[72] Giovine, L., Fabietti, F., Food Control 2005, 16, 267-272.

[73] Carrasco-Pancorbo, A., Segura-Carretero, A., Fernandez-Gutierrez, A., J. Sep. Sci. 2005, 28, 925-934..

[74] Carrasco-Pancorbo, A., Cruces-Blanco, C., Segura-Carretero, A., Fernandez-Gutierrez, A., J. Agric. Food Chem. 2004, 52, 6687-6693.

[75] Watson, D.J., Bushway, A.A., Bushway, R.J., J. Liq. Chromatogr. Rel. Technol. 2004, 27, 113- 121.

[76] Juang, L.J., Sheu, S.J., Lin, T.C., J. Sep. Sci. 2004, 27, 718-724.

[77] Peng, Y., Liu, F., Peng, Y., Ye, J., Food Chem. 2005, 92, 169-175.

[78] Peng, Y., Chu, Q., Liu, F., Ye, J., Food Chem. 2004, 87, 135-139. 
[79] Herrero, M., Ibáñez, E., Señoráns, J., Cifuentes, A., J. Chromatogr. A. 2004, 1047, 195-203.

[80] Truus, K., Vaher, M., Koel, M., Mahar, A., et al, Anal. Bioanal. Chem. 2004, 379, 849-852.

[81] Gotti, R., Fiori, J., Mancini, F., Cavrini,V., Electrophoresis 2004, 25, 3282- 3291.

[82] Strom, A., Williams, M.A.K. Carbohydrate Res. 2004, 339, 1711-1716.

[83] Andersen, K.E., Bjergegaard, C., Moller, P., Sorensen, J.C., et al, J. Agric.Food Chem. 2003, 51, 6391-6397.

[84] Hyun-Joo, A., Franz, A.H., Lebrilla, C.B., J. Chromatogr. A 2003, 1004, 121-129.

[85] Khandurina, J., Anderson, A.A., Olson, N.A., Stege, J.T., et al, Electrophoresis 2004, 25, 3122-3127.

[86] Zhang, L.Y., Xu, J., Zhang, L.H., Zhang, W.B., et al, J. Chromatogr. B 2003, 793, 159-165.

[87] Corradini, C., Bianchi, F., Matteuzzi, D., Amoretti, A., et al, J. Chromatogr. A 2004, 1054, $165-173$.

[88] Moo, Y. K., Varenne, A., Daniel, R., Gareil, P., J. Sep. Sci. 2003, 26, 1154-1162.

[89] Andersen, K.E., Bjergegaard, C., Sorensen, H., J. Agric.Food Chem. 2003, 51, 7234-7239. 
[90] de Garcia-Moreno, M.V., Castro-Mejias, R., Natera-Marin, R., Garcia-Barroso, C., Eur.Food Res.Technol. 2002, 215, 255-259.

[91] Cortacero-Ramirez, S., Segura-Carretero, A., Cruces-Blanco, C., Hernainz-Bermudez de Castro, M., et al, J. Sci. Food Agric. 2005, 85, 517-521.

[92] Cao, Y., Wang, Y., Chen, X., Ye, J. Food Chem. 2004, 86, 131-136.

[93] Chu, Q., Fu, L., Guan, Y., Ye, J., J. Sep. Sci. 2005, 28, 234-238.

[94] Cortacero-Ramirez, S., Segura-Carretero, A., Cruces-Blanco, C., Hernainz-Bermudez de Castro, M., et al, Food Chem. 2004, 87, 471-476.

[95] García-Cañas, V., Cifuentes, A., González, R., Anal. Chem. 2004, 76, 2306-2313.

[96] García-Cañas, V., González, R., Cifuentes, A., Electrophoresis 2004, 25, 2219-2226.

[97] García-Cañas, V., Macian, M., Chenoll, E., Aznar, R., et al, J. Agric. Food Chem. 2004, 52, 5582-5587.

[98] Funes-Huacca, M., de Almeida-Regitano, L.C., Mueller, O., Carrilho, E., Electrophoresis 2004, 25, 3860-3864.

[99] Martin, A., Jurado, M., Rodriguez, M., Nunez, F., et al, J. Food Prot. 2004, 67, 2234-2239. 
[100] Alarcón, B., García-Cañas,V., Cifuentes, A., González, R., et al, J. Agric. Food Chem. 2004, 52, 7180-7186.

[101] Lindstedt, B.A., Vardund, T., Aas, L., Kapperud, G., J. Microbiol. Met. 2004, 59, 163-172.

[102] Yu-Ling, S., Chich-Sheng, L., J. Agric.Food Chem. 2003, 51, 1771-1776.

[103] Salmanowicz, B.P., Moczulski, M., J. Chromatogr. A 2004, 1032, 313-318.

[104] Su, A.K., Chang, Y.S., Lin, C.H., Talanta 2004, 64, 970-974.

[105] Cataldi, T.R.I., Nardiello, D., Scrano, L., Scopa, A., J. Agric. Food Chem. 2002, 50, 66436647.

[106] Sadecka, J., Karasova, G., Polonsky, J., Eur. Food Res.Technol. 2003, 216, 440- 444.

[107] Versari, A., Mattioli, A., Parpinello, G.P., Galassi, S., Food Control 2004, 15, 355-358.

[108] Izco, J.M., Tormo, M., Harris, A., Tong, P.S., et al, J. Dairy Sci. 2003, 86, 86-95.

[109] Cortacero-Ramirez, S., Segura-Carretero, A., Hernainz-Bermudez de Castro, M., FernandezGutierrez, A., J. Chromatogr. A 2005, 1064, 115-119.

[110] Galli, V., Barbas, C., J. Chromatogr. A 2004, 1032, 299-304. 
[111] Buiarelli, F., Cartoni, G., Coccioli, F., Jasionowska, R., J. Sep. Sci. 2003, 26, 425- 428.

[112] Baoguo, S., Macka, M., Haddad, P.R., J. Chromatogr. A 2004, 1039, 201-208.

[113] Zu-Liang, C., Ravendra, N., Anal. Bioanal. Chem.. 2003, 374, 520-525.

[114] Fung, Y.S., Lau, K.M., Electrophoresis 2003, 24, 3224-3232.

[115] de Villiers, A., Lynen, F., Crouch, A., Sandra, P., Eur.Food Res.Technol. 2003, 217, 535540.

[116] Negro, A., Paz, E., Rabanal, B., J. Liq. Chrom.Rel. Technol. 2003, 26, 709-722.

[117] Bianchi, F., Careri, M., Corradini, C., J. Sep. Sci. 2005, 28, 898-904.

[118] Unterholzner, V., Macka, M., Haddad, P.R., Zemann, A., Analyst 2002, 127, 715-718.

[119] Sawada, H., Nogami, C., Anal. Chim. Acta 2004, 507, 191-198.

[120] Hernández-Borges, J., Rodríguez-Delgado, M.A., García-Montelongo, F.J., Cifuentes, A., Electrophoresis 2004, 25, 2065-2076.

[121] Hernández-Borges, J., Cifuentes, A., García-Montelongo, F.J. Rodríguez-Delgado, M.A., Electrophoresis 2005, 26, 980-989. 
[122] Hernández-Borges, J., Rodríguez-Delgado, M.A., García-Montelongo, F.J., Cifuentes, A., J. Sep. Sci. 2005, 28, 948-956.

[123] Navarrete-Casas, M., Segura-Carretero, A., Cruces-Blanco, C., Fernandez-Gutierrez, A., Pest. Manag. Sci. 2005, 61, 197-203.

[124] Segura-Carretero, A., Cruces-Blanco, C., Cortacero-Ramirez, S., Carrasco-Pancorbo, A., et al, J. Agric. Food Chem. 2004, 52, 5791-5795.

[125] Kaltsonoudis, C.K., Lamari, F.N., Prousalis, K.P., Karamanos, N.K., et al, Chromatographia 2003, 57, 181-184.

[126] da Silva, C.L., de Lima, E.C., Tavares, M.F.M., J. Chromatogr. A 2003, 1014, 109-116.

[127] Bagheri, H., Saraji, M., Barcelo, D., Chromatographia 2004, 59, 283-289.

[128] Shakulashvili, N., Revia, R., Steiner, F., Engelhardt, H., Chromatographia 2004, 60, 145150.

[129] Rodriguez, R., Manes, J., Pico,Y. Anal. Chem. 2003, 75, 452-459.

[130] Goodwin, L., Startin, J.R., Keely, B.J., Goodall, D.M., J. Chromatogr. A 2003, 1004, 107119.

[131] Safarpour, H., Asiaie, R., Katz, S., J. Chromatogr. A 2004, 1036, 217-222. 
[132] Kowalski, P., Oledzka, I., Lamparczyk, H., J. Pharm. Biomed. Anal. 2003, 32, 937-947.

[133] Ferdig, M., Kaleta, A., Thuy D.T.V., Buchberger, W., J. Chromatogr. A 2004, 1047, 305311.

[134] Fuh, M.R.S., Chu, S.Y., Anal. Chim. Acta 2003, 499, 215-221.

[135] Sanches, P.J., Rios, A., Valcarcel, M., Zanin, K.D., Caramao, E.B., J. Chromatogr. A 2003, 985, 503-512.

[136] Maragos, C.M., Food Addit.Cont. 2004, 21, 803-810.

[137] Guo, L., Matysik, F.M., Glaeser, P. Anal. Bioanal. Chem. 2004, 380, 669-676.

[138] Buszewski, B., Szumski, M., Klodzinska, E., Dahm, H., J. Sep. Sci. 2003, 26, 1045-1049.

[139] Palenzuela, B., Simonet, B.M., Garcia, R.M., Rios, A., et al, Anal. Chem. 2004, 76, 30123017.

[140] Huang, H.Y., Shih, Y.C., Chen, Y.C., J. Chromatogr. A 2002, 959, 317-325.

[141] Patsovskii, A.P., Rudometova, N.V., Kamentsev, Y.S., J. Anal. Chem. 2004, 59, 150-154. 
[142] de Villiers, A., Alberts, F., Lynen, F., Crouch, A., et al, Chromatographia 2003, 58, 393397.

[143] Chou, S.S., Lin, Y.H., Cheng, C.C., Hwang, D.F., J. food Sci. 2002, 67, 1314-1318.

[144] Jager, A.V., Tonin, F.G., Tavares, M.F.M., J. Sep. Sci. 2005, 28, 957-965.

[145] Huang, H.Y., Chuang, C.L., Chiu, C.W., Chung, M.C., Electrophoresis 2005, 26, 867-877.

[146] Stroka, J., Dossi, N., Anklam, E., Food Addit. Cont. 2003, 20, 524-527.

[147] Huang, H.Y., Chuang, C.L.., Chiu, C.W., Yeh, J.M., Food. Chem. 2005, 89, 315-322.

[148] Flottmann, D. Hins, J., Meissner, T., Dietrich, C., et al, Chromatographia 2004, 60, 253-256.

[149] Vallejo-Cordoba, B., Mazorra-Manzano, M.A., Gonzalez-Cordova, A.F., J. Agric. Food Chem. 2004, 52, 5787-5790.

[150] Sung, M.W., Li, P.C.H. Electrophoresis 2004, 25, 3434-3440.

[151] Viberg, P., Nilsson, S., Skog, K., Anal. Bioanal. Chem. 2004, 378, 1729-1734

[152] Bermudo, E., Ruiz-Calero, V., Puignou, L., Galceran, M.T., Electrophoresis 2004, 25, 3257-3262. 
[153] Lynen, F., van Thuyne, W., Borremans, F., Vanhoenacker, G., et al, J. Sep. Sci. 2003, 26, 53-60.

[154] Girard, M., Turgeon, S.L., Gauthier, S.F., J. Agric. Food Chem. 2003, 51, 6043-6049.

[155] Davila-El-Rassi, G.M., Mitchum, J.A., Escober, M.C., Rayas-Duarte, P., et al, J. Liq. Chromatogr. Rel. Technol. 2003, 26. 2465-2479.

[156] Armstrong, D. W., Chang, C. D., Li, W. L., J. Agric. Food Chem. 1990, 38, 1674-1677

[157] Diagone, C.A., Ogawa, C.A., Lancas, F.M., J. Liq. Chromatogr. \& Rel. Technol. 2003, 26, 505-516.

[158] Kodama, S., Yamamoto, A., Ohura, T., Matsunaga, A., et al, J. Agric. Food Chem. 2003, 51, 6128-6131.

[159] Aturki, Z., Sinibaldi, M., J. Sep. Sci. 2003, 26, 844-850.

[160] Fan, L., Cheng, Y., Chen, H., Liu, L., et al., Electrophoresis 2004, 25, 3163-3167.

[161] Raab, T., Schmitt, U., Hauck, T., Knecht, A., et al, Chromatographia 200, 57, 501-504.

[162] Kodama, S., Yamamoto, A., Matsunaga, A., Yanai, H., Electrophoresis 2004, 25, 28922898. 
[163] Cortacero-Ramirez, S., Segura-Carretero, A., Cruces-Blanco, C., Romero-Romero, M.L., Anal. Bioanal. Chem. 2004, 380, 831-837.

[164] Cortacero-Ramirez, S., Segura-Carretero, A., Cruces-Blanco, C., Hernainz-Bermudez de Castro, M., Electrophoresis 2004, 25, 1867-1871

[165] Pyell, U., Pletsch-Viehmann, B., Ramus, U., J. Sep. Sci. 2002, 25, 1035-1042.

[166] Bianco, G., Schmitt-Kopplin, P., Crescenzi, A., Comes, S., et al, Anal. Bioanal. Chem. 2003, 375, 799-804.

[167] Simonet, B.M., Rios, A., Grases, F., Valcarcel, M., Electrophoresis 2003, 24, 2092-2098.

[168] Roseiro, L.B., Gomez-Ruiz, J.A., Garcia-Risco, M., Molina, E., Lait 2003, 8, 343-350.

[169] Cao, Y.H., Zhang, X., Chu, Q.C., Fang, Y.Z., et al, Electroanalysis 2003, 15, 898-902.

[170] Ohman, M., Wan, H., Hamberg, M., Blomberg, L.G., Journal of Separation Science 2002, 25, 499-506

[171] Segura-Carretero, A., Cruces-Blanco, C., Soriano-Pena, M., Cortacero-Ramirez, S., et al, J. Agric. Food Chem. 2004, 52, 1419-1422.

[172] Ge, L., Yong, J. W. H., Tan, S. N., Yang, X. H.., et al, J. Chromatogr. A 2004, 1048, 119126. 
[173] Shang, X., Yuan, Z., Anal. Let. 2003, 36, 203-214.

[174] Mandrioli, R., Musenga, A., Ferranti, A., Lasaponara, S.S., et al., J. Sep. Sci., 2005, 28, 966 $972-$

[175] Qin, J.H., Leung, F.C., Fung, Y.S., Zhu, D.R., Lin, B.C., Anal. Bioanal. Chem., 2005, 381, 812-819.

[176] Obeid, P.J., Christopoulos, T.K., Ioannou, P.C., Electrophoresis 2004, 25, 922-930.

[177] Kato, M., Gyoten, Y., Sakai-Kato, K., Toyo'oka, T., J. Chromatogr. A 2003, 1013, 183-189.

[178] Masar, M., Zuborova, M., Kaniansky, D., Stanislawski, B., J. Sep. Sci. 2003, 26, 647-652.

[179] Masar, M., Poliakova, K., Dankova, M., Kaniansky, D., Stanislawski, B., J. Sep. Sci. 2005, 28, $905-914$.

[180] Masar, M., Dankova, M., Olvecka, E., Stachurova, A., et al, J. Chromatogr. A 2004, 1026, 31-39.

[181] Tanyanyiwa, J., Hauser, P.C., Anal. Chem. 2002, 74, 6378-6382.

[182] Scampicchio, M., Wang, J., Mannino, S., Chatrathi, M.P., J. Chromatogr. A 2004, 1049, 189-194. 
[183] Wang, J., Chen, G., Wan, M., Chatrathi, M.P., Analyst. 2004, 129, 512-515.

[184] Burns, M., Shanahan, D., Valdivia, H., Harris, N., Eur. Food Res. Technol. 2003, 216, 428433.

[185] Gardeniers, H., Van den Berg, A., Int. J. Envir. Anal. Chem. 2004, 84, 809-819.

[186] Sung, W.C., Makamba, H., Chen, S.H., Electrophoresis, 2005, 26, 1783-1791.

[187] Bossi, A., Castelletti, L., Piletsky, S.A., Turner, A.P.F., et al, Electrophoresis 2003, 24, 33563363.

[188] Jayawickrama, D.A., Sweedler, J.V., J. Chromatogr. A 2003, 1000, 819-840. 


\section{FIGURE LEGENDS}

Figure 1. (A) Chiral MEKC-LIF separation of standard FITC-amino acids. (B) Electropherogram of the peaks coming from nonreacting FITC (marked with asterisks). Conditions were the folllowing: capillary, $l_{d}, 40 \mathrm{~cm}, l_{t}, 50 \mathrm{~cm}$ with $50 \mu \mathrm{m}$ i.d.; running buffer, $100 \mathrm{mM}$ sodium tetraborate, $30 \mathrm{mM}$ SDS at pH 9.4 with $20 \mathrm{mM}$ beta-CD; capillary temperature, $15{ }^{\circ} \mathrm{C}$; run voltage, $20 \mathrm{kV}$; injection at 0.5 psi for $5 \mathrm{~s}$ of FITC derivatized (1) D-Arg, (2) L-Arg, (3) L-Pro, (4) D-Pro, (5) D-Asn, (6) GABA, (7) L-Asn, (8) D-Ser, (9) D-Ala, (10) L-Ser, (11) L-Ala, (12) D-Glu, (13) LGlu, (14) D-Asp, (15) L-Asp, (*) peak from FITC. Concentration of amino acids injected $(\mu \mathrm{M})$ : D,L-Arg (1.06), D,L-Pro (1.9), GABA (0.65), Asn (0.77), Ser (0.39), Ala (0.27), Glu (0.17) and Asp (0.59). LIF detection at $488 \mathrm{~nm}$ (excitation wavelength) and $520 \mathrm{~nm}$ (emission wavelength). Redrawn from reference [24].

Figure 2. CZE electropherogram of phenolic fraction extracted from real olive oil sample by LLE: (a) Arbequina; (b) Lechin de Sevilla; (c) Picual; (d) Hojiblanca; (e) Lechin de Granada; (f) Cornicabra; (g) refined olive oil; (h) mixture of refined and virgin olive oils. Separation conditions: capillary, $57 \mathrm{~cm} \mathrm{x} 75 \mu \mathrm{m}$; applied voltage, $25 \mathrm{kV}$; applied temperature, $25{ }^{\circ} \mathrm{C}$; buffer, $25 \mathrm{mM}$ sodium borate ( $\mathrm{pH}$ 9.60); hydrodynamic injection, 0.5 psi for 8 s. Detection was performed at 210 nm. Peaks: 1, trans-cinnamic acid; 2, 4-hydroxyphenylacetic acid; 3, sinapinic acid; 4, gentisic acid; 5, (+)-taxifolin; 6, ferulic acid; 7, o-coumaric acid; 8, p-coumaric acid; 9, vanillic acid; 10, caffeic acid; 11, 4-hydroxybenzoic acid; 12, dopac; 13, gallic acid; 14, protocatechuic acid. Redrawn from reference [74]. 
Figure 3. CE-MS electropherograms from an orange juice sample adulterated with $0.8 \%$ (with respect to the total amino acid content) of D/L-Asp. CE-MS conditions: CE conditions: polymercoated capillary (87cm ld, $50 \mu \mathrm{m}$ ID); BGE, $100 \mathrm{mM}$ ammonium acetate buffer at pH 6 with 5mM $\beta$-CD; running voltage, $215 \mathrm{kV}$, injection at 0.5 psi during $18 \mathrm{~s}$ of FITC-amino acids. MS conditions: positive ion mode; sheath liquid methanol-water (1:1 v/v) with 25\% BGE without $\beta-\mathrm{CD}$, at a flow rate of $3.5 \mathrm{~mL} / \mathrm{min}$, dry gas flow at $3 \mathrm{~L} / \mathrm{min}$; temperature at $350{ }^{\circ} \mathrm{C}$; mass scan, 150-700. Redrawn from ref [26].

Figure 4: (A) Schematic diagram of the in-housed developed CE chip and the holding apparatus. The time required to exchange chips is less than 2 min. (B) Schematic representation of the inhouse developed LIF detection system. The detection system allows for rapid mounting of the chip and offers flexibility for any modification. (C) Typical electropherogram for the optimized separation of the $\phi X 174$ DNA, HaeIII digest marker (20 ng/mL). DNA fragments (72-1353 bp) are separated and detected within a period of $45-70 \mathrm{~s}$ from the initiation of separation. $0.25 \%$ hydroxypropyl methylcellulose in MES/Tris buffer $(80 / 40 \mathrm{mM})$ at $\mathrm{pH} 6.1$ containing a 5000-fold dilution of the SG1 stock was used as the running buffer. Injection was carried out for $60 \mathrm{~s}$ followed by separation at $400 \mathrm{~V} / \mathrm{cm}$. Redrawn from reference [176]. 
Table 1. Reviews on capillary electromigration methods in food analysis and related areas.

\section{Subject}

Ref.

General review on CE in food analysis

Analysis of pesticides in foods by CE

Chiral electromigration methods in food analysis

Detection of genetically modified organisms in foods

Combined use of molecular techniques and CE in food analysis

Analysis of natural antioxidants by capillary electromigration methods

Analysis of beer components by CE methods

Capillary electrophoresis-mass spectrometry in food analysis

Determination of urea pesticide residues in vegetable and water samples

CE for short-chain organic acids and inorganic anions

Analysis of antibiotics by CE

Amino acid analysis by CE

Analysis of low molecular weight carbohydrates in foods and beverages

Food additives and micronutrients

Chiral analysis of aliphatic short chain organic acids by CE

Organic contaminants in food by CE

CE in food authenticity

CE for the analysis of meat authenticity

CE in routine food analysis 
Table 2: Food proteins and peptides analyzed by CE

\begin{tabular}{|c|c|c|c|}
\hline $\begin{array}{c}\text { Proteins or } \\
\text { peptides analyzed }\end{array}$ & Sample & CE conditions & Ref \\
\hline $\begin{array}{l}\text { Basic and acidic } \\
\text { proteins (whey } \\
\text { proteins) }\end{array}$ & Milk & CE-UV using new coated capillaries & [33] \\
\hline Bovine caseins & Dairy products & $\begin{array}{l}\text { CE-UV, central composite designs and } \\
\text { response surface methodology. Buffer: } 10 \mathrm{mM} \\
\text { phosphate buffer at pH } 3.0 \text { with } 0.05 \%(\mathrm{w} / \mathrm{v}) \\
\text { hydroxypropyl methyl cellulose. }\end{array}$ & [34] \\
\hline $\begin{array}{l}\text { Para-kappa- } \\
\text { Casein and } \\
\text { related peptides }\end{array}$ & $\begin{array}{l}\text { Stored raw, } \\
\text { pasteurized and } \\
\text { UHT milk }\end{array}$ & CE-UV & [35] \\
\hline $\begin{array}{l}\text { Proteolysis on } \\
\text { whey protein }\end{array}$ & $\begin{array}{l}\text { Raw and UHT } \\
\text { milk }\end{array}$ & CE-UV & [36] \\
\hline $\begin{array}{l}\text { Casein fractions } \\
\text { and peptides }\end{array}$ & Cheeses & CE-UV(with urea) & [37] \\
\hline Casein fractions & Cheeses & CE-UV(with urea) & [38] \\
\hline $\begin{array}{l}\text { Casein and whey } \\
\text { proteins }\end{array}$ & $\begin{array}{l}\text { Mares' milk and } \\
\text { asses' milk }\end{array}$ & CGE-UV and CE-UV (with urea) & [39] \\
\hline Whey proteins & Cheese & $\begin{array}{l}\text { CE with on-capillary derivatization and laser- } \\
\text { induced fluorescence detection }\end{array}$ & [40] \\
\hline $\begin{array}{l}\text { Bovine beta- } \\
\text { lactoglobulin }\end{array}$ & Infant formulas & $\begin{array}{l}\text { CE with on-capillary derivatization and laser- } \\
\text { induced fluorescence detection }\end{array}$ & [41] \\
\hline $\begin{array}{l}\text { Water soluble } \\
\text { proteins } \\
\text { (globulins) }\end{array}$ & Cereals & $\begin{array}{l}\text { CE-UV with a buffer composed of } 50 \mathrm{mM} \\
\text { sodium phosphate, } \mathrm{pH} 2.5+20 \% \text { acetonitrile } \\
(\mathrm{v} / \mathrm{v})+0.05 \%(\mathrm{w} / \mathrm{v}) \text { hydroxypropylmethyl- } \\
\text { cellulose }+50 \mathrm{mM} \text { hexane sulfonic acid }\end{array}$ & [42] \\
\hline Gliadins & $\begin{array}{l}\text { Wheat from } 24 \\
\text { cultivars }\end{array}$ & CE-UV & [43] \\
\hline Hordeins & $\begin{array}{l}\text { Three barley } \\
\text { species }\end{array}$ & $\begin{array}{l}\text { CE-UV using 0.1M phosphate-glycine buffer } \\
\text { (pH 2.5), 20\% acetonitrile and 0.05\% } \\
\text { hydroxypropylmethyl-cellulose }\end{array}$ & [44] \\
\hline $\begin{array}{l}\text { Gliadins and } \\
\text { albumins }\end{array}$ & $\begin{array}{l}23 \text { wheat } \\
\text { cultivars }\end{array}$ & CE-UV & [45] \\
\hline $\begin{array}{l}\text { High molecular } \\
\text { weight glutenins }\end{array}$ & Wheat & $\begin{array}{l}\text { CE-UV using phosphate-glycine buffer ( } \mathrm{pH} \\
\text { 2.5) and uncoated fused-silica capillaries }\end{array}$ & [46] \\
\hline $\begin{array}{l}\text { Cereal protein } \\
\quad \text { extract }\end{array}$ & Wheat flour & $\begin{array}{l}\text { CE-UV using } 40 \mathrm{mM} \text { aspartic acid, } 6 \mathrm{M} \text { urea } \\
\text { and } 0.5 \% \text { hydroxyethylcellulose at } 60^{\circ} \mathrm{C}\end{array}$ & [47] \\
\hline Gliadins & Hulled wheats & $\begin{array}{c}\text { CE-UV using 40mM aspartic acid, 4M urea, } \\
0.5 \%(\mathrm{w} / \mathrm{v}) \text { HEC and } 20 \%(\mathrm{v} / \mathrm{v})\end{array}$ & [48] \\
\hline Gliadins & $\begin{array}{l}\text { Wheat (Triticum } \\
\text { species) }\end{array}$ & $\begin{array}{c}\text { Acetonitrile at } 42^{\circ} \mathrm{C} \text {. } \\
\text { CE-UV using acidic or isoelectric buffers }\end{array}$ & [49] \\
\hline Proteins & Cider & CGE-UV using linear polyacrylamide & {$[50]$} \\
\hline Bioactive peptide & Vicia narbonensis & CE-UV and CE-MS with ESI compatible buffer & {$[51]$} \\
\hline
\end{tabular}




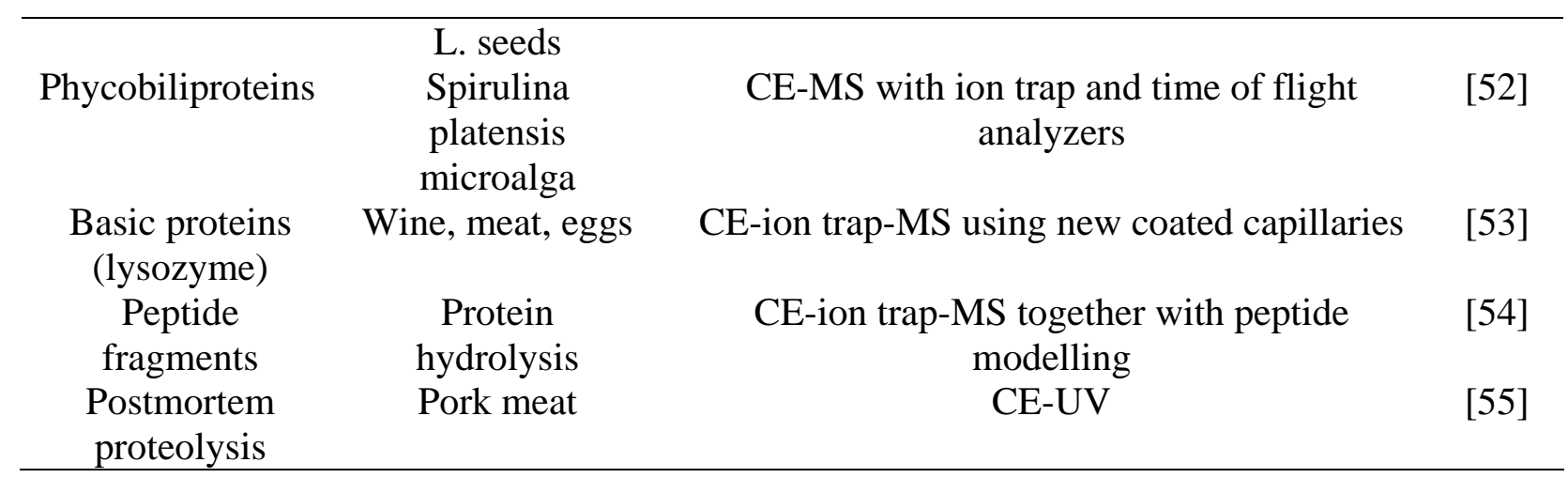


Table 3. Chiral capillary electromigration methods in food analysis.

\begin{tabular}{|c|c|c|c|c|}
\hline Analytes & Chiral selector & CE conditions & Food & Ref. \\
\hline Amino acids & beta-cyclodextrin & MEKC-LIF & $\begin{array}{c}\text { Orange juices from different } \\
\text { origin }\end{array}$ & [24] \\
\hline Amino acids & beta-cyclodextrin & MEKC-LIF & $\begin{array}{c}\text { Nectar, concentrate and natural } \\
\text { orange juices }\end{array}$ & [25] \\
\hline Amino acids & beta-cyclodextrin & CE-MS & Natural orange juice & [26] \\
\hline $\begin{array}{c}\text { Monoterpenes } \\
\text { (alpha-therpineol, } \\
\text { linalool, carvone } \\
\text { and citral) }\end{array}$ & $\begin{array}{l}\text { methyl-beta- } \\
\text { cyclodextrin }\end{array}$ & CE-UV & Citrus fruits and essential oils & {$[157]$} \\
\hline Imazalil residue & $\begin{array}{l}\text { 2-hydroxypropyl- } \\
\text { beta-cyclodextrin }\end{array}$ & CE-UV & Oranges & {$[158]$} \\
\hline $\begin{array}{l}\text { Flavanone-7-O- } \\
\text { glycosides }\end{array}$ & $\begin{array}{l}\text { sulfobutyl ether- } \\
\text { beta-cyclodextrin }\end{array}$ & CE-UV & $\begin{array}{c}\text { Citrus juices (lemon, grapefruit } \\
\text { and orange) }\end{array}$ & {$[159]$} \\
\hline D-, L-aspartic acid & beta-cyclodextrin & CE-UV & Amino acids mixture & {$[160]$} \\
\hline $\begin{array}{l}\text { 2,5-dimethyl-4- } \\
\text { hydroxy-3(2H)- } \\
\text { furanone }\end{array}$ & $\begin{array}{l}\text { heptakis-(2,3-O- } \\
\text { diacetyl-6-sulfato)- } \\
\text { beta-cyclodextrin }\end{array}$ & CE-UV & $\begin{array}{c}\text { Strawberries and yeast } \\
\text { Zygosaccharomyces rouxii }\end{array}$ & {$[161]$} \\
\hline $\begin{array}{l}\text { Catechin and } \\
\text { epicatechin }\end{array}$ & $\begin{array}{l}\text { 6-O-alpha-D- } \\
\text { glucosyl-beta- } \\
\text { cyclodextrin }\end{array}$ & MEKC-UV & Tea drinks & {$[162]$} \\
\hline
\end{tabular}


Table 4. Applications of microchips in food analysis.

\begin{tabular}{cccc}
\hline Chip analysis mode & Analyte & Food & Ref. \\
\hline CGE-LIF & DNAs (after PCR) & Ginseng species & {$[175]$} \\
CGE-LIF & DNAs (after PCR) & GMOs & {$[176]$} \\
MEKC-LIF & Derivatized amino acids & Green tea & {$[177]$} \\
CE-CD & Oxalate & Beers & {$[178]$} \\
CE-CD & Tartrate, malate, succinate, acetate, & Wines & {$[179]$} \\
& citrate, and lactate & & \\
CE-CD & Free sulfite & Wines & {$[180]$} \\
CE-CD & Citric and lactic acids & Standards & {$[181]$} \\
CE-AD & Red wine & {$[182]$} \\
& Chlorogenic, gentisic, ferulic, and & & {$[183]$} \\
CE-AD & vanillic acids & Standards & {$[98]$} \\
Commercial LabChip & DNAs (after PCR) from spoilage & Orange juices & \\
& bacterium Alicyclobacillus & & \\
Commercial LabChip & acidoterrestris & Roundup Ready & {$[184]$} \\
& DNAs (after PCR) & Soya (GMO) & \\
\hline
\end{tabular}




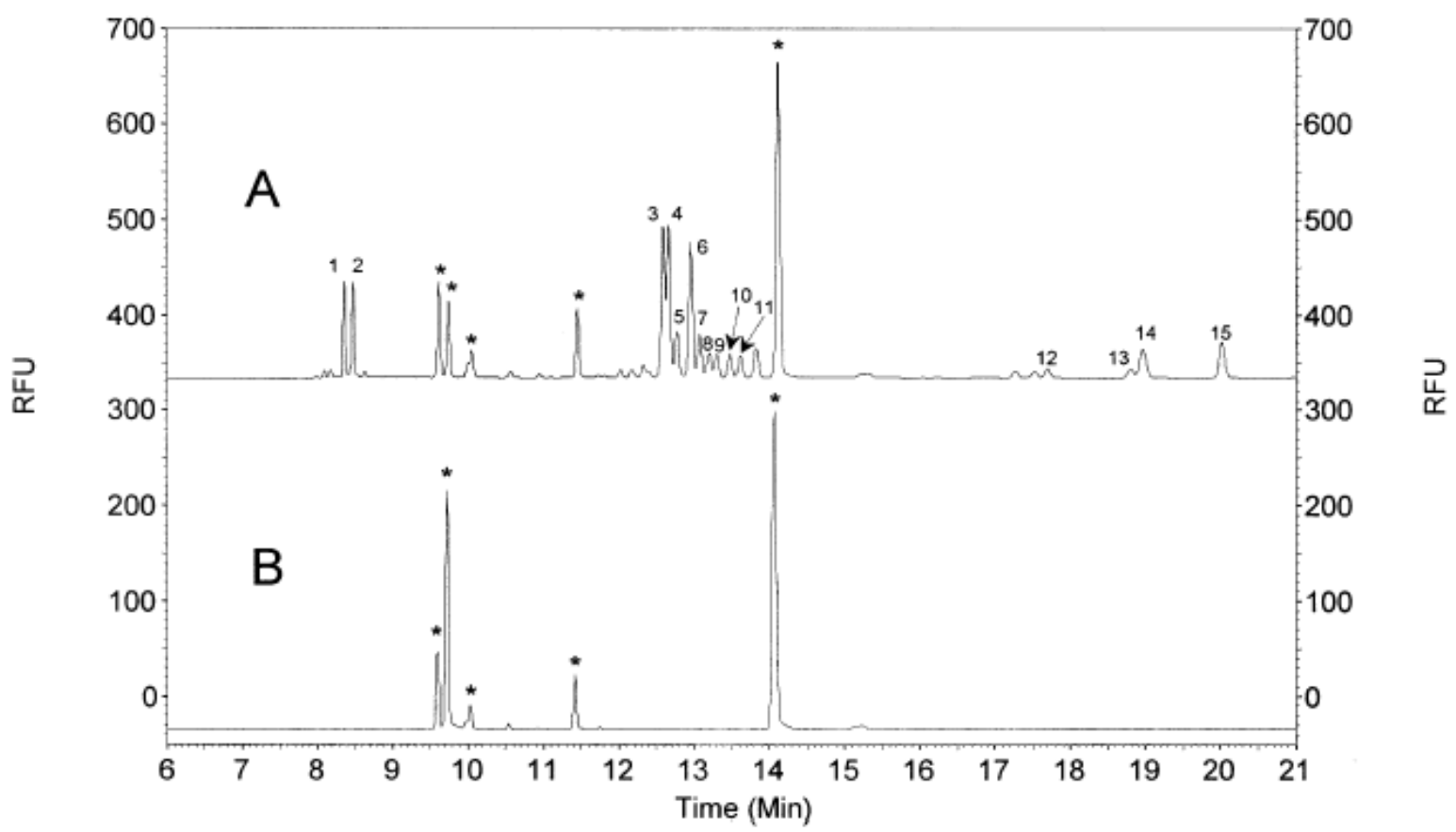

Figure 1 

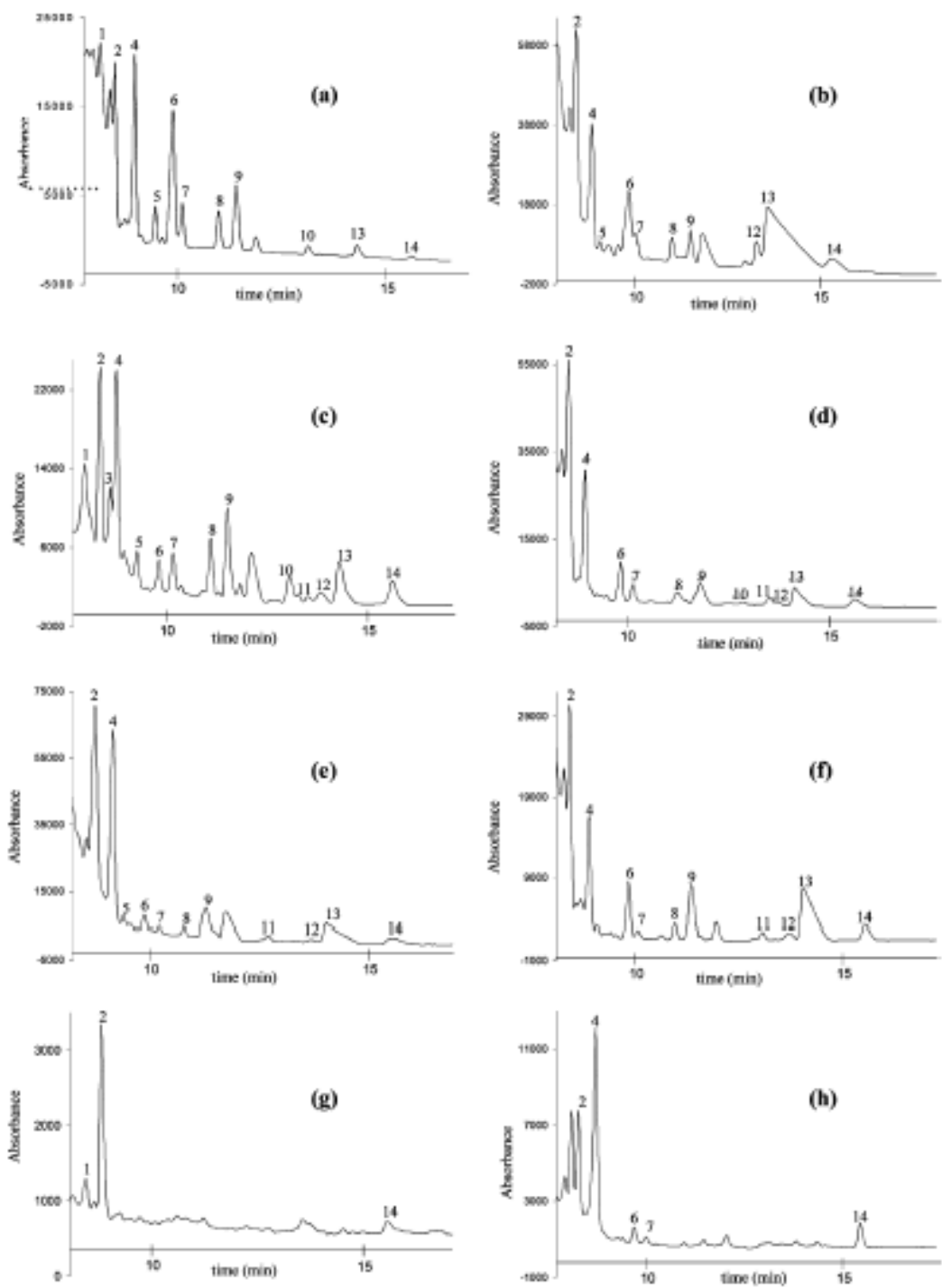

Figure 2 


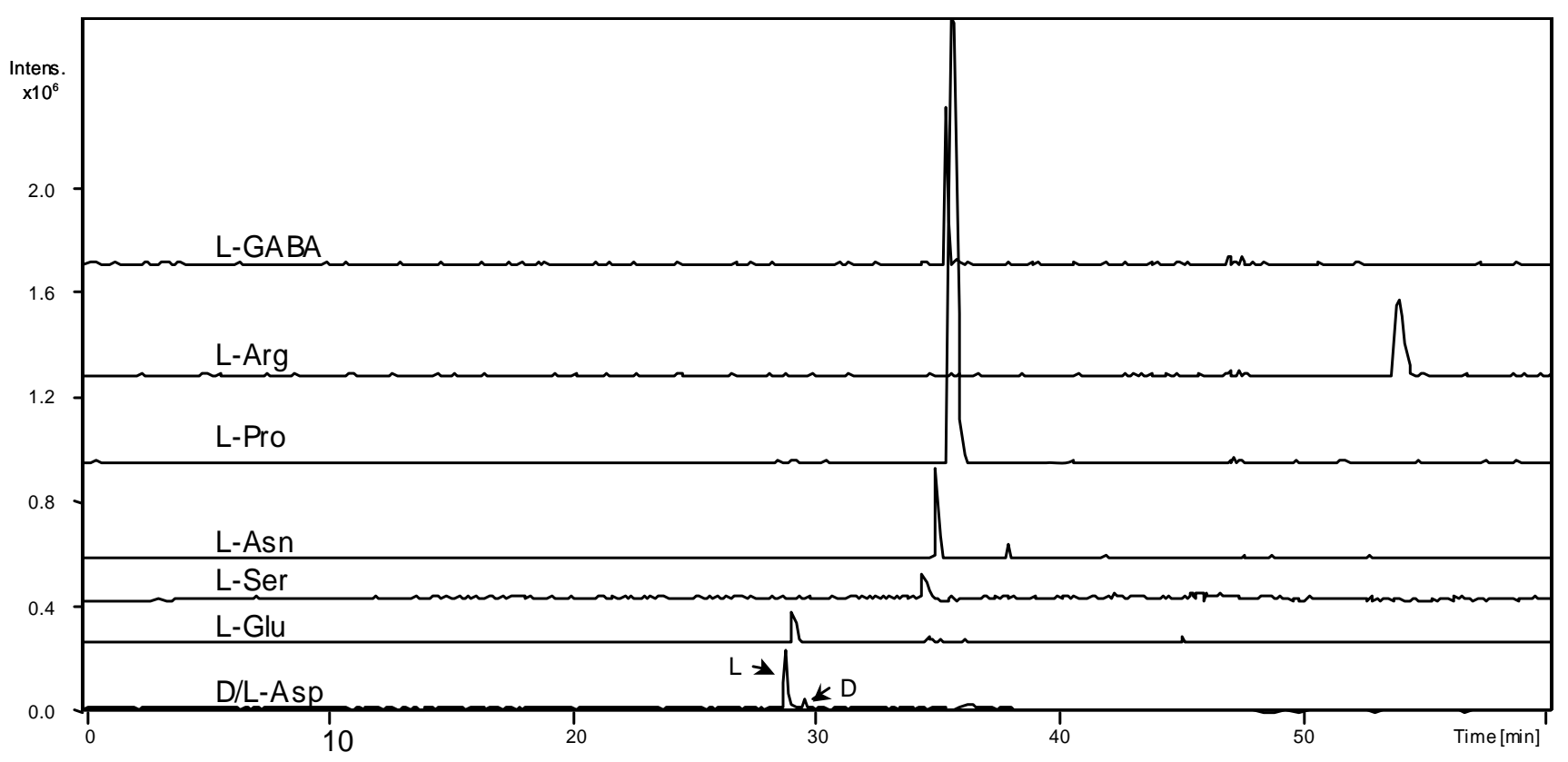

Figure 3 

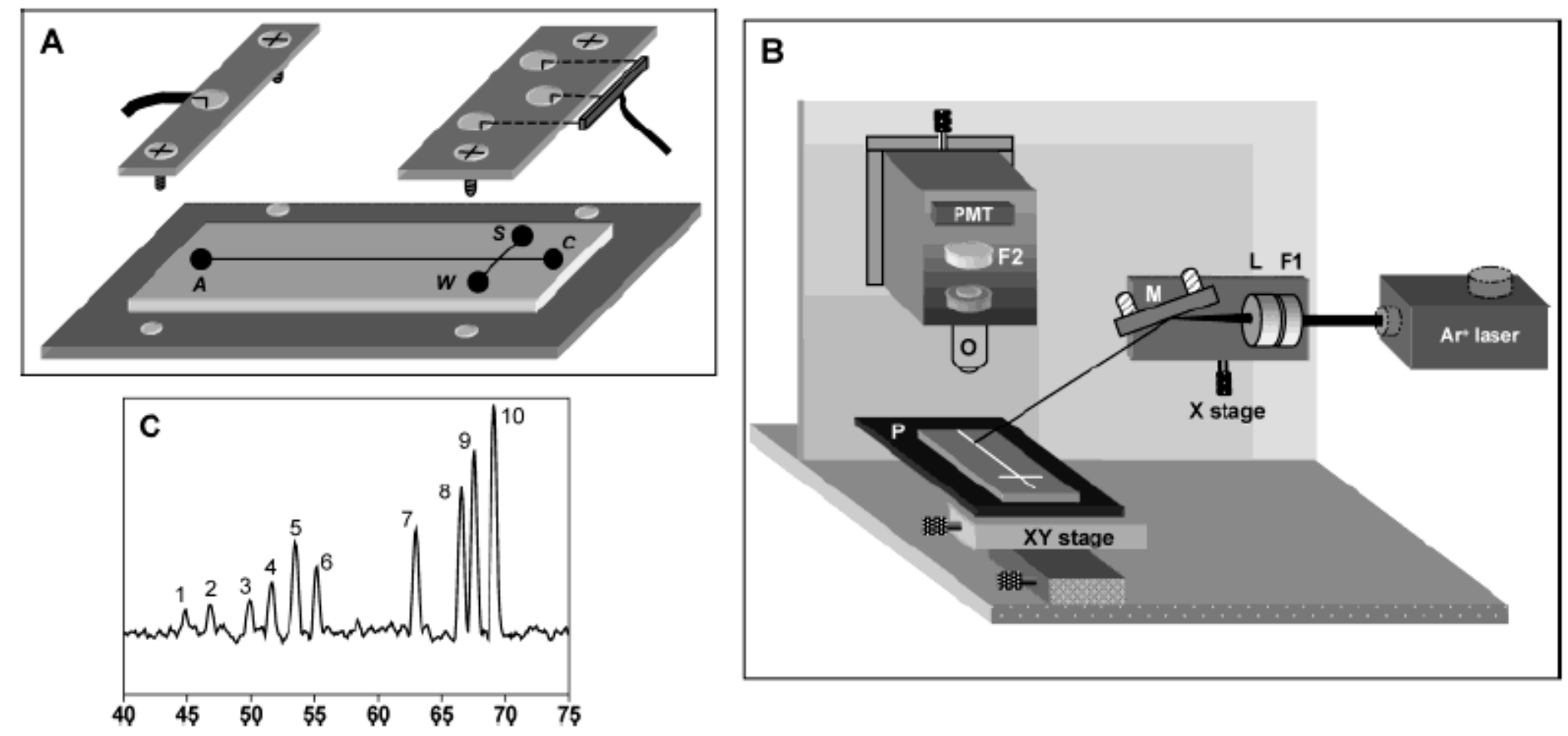

Figure 4 